\title{
Targeting autophagy with hydroxychloroquine potentiates ponatinib- and axitinib-induced cell death in BCR-ABL T315I-containing CML
}

biqing han ( $\nabla$ hanbiqingwxp@163.com )

Second Affiliated Hospital of Harbin Medical University https://orcid.org/0000-0003-4609-6207

Dandan Yao

Second Affiliated Hospital of Harbin Medical University

Yongfang Jiang

Second Affiliated Hospital of Harbin Medical University

Liyan Chen

Second Affiliated Hospital of Harbin Medical University

Shuqiu Zhou

Fourth Hospital of Daqing

Jingjing Li

Tianjin Fourth Central Hospital

Limengmeng Wang

Zhejiang University

Shan Fu

Zhejiang University

Yu Lin

Zhejiang University

He Huang

Zhejiang University

Haibin Dai

Second Affiliated Hospital of Harbin Medical University

\section{Research Article}

Keywords: Autophagy, Ponatinib, Axitinib, CML with T315I mutation

Posted Date: April 20th, 2021

DOI: https://doi.org/10.21203/rs.3.rs-428830/v1 
License: (c) (i) This work is licensed under a Creative Commons Attribution 4.0 International License. Read Full License 


\section{Abstract \\ Purpose}

Because of the dose-dependent increased risk of cardiovascular events we tried to lower the dose of ponatinib without reducing its efficacy in the treatment of BCR-ABL T315I-containing CML. Combination with hydroxychloroquine can enhance the efficiency of ponatinib and axitinib through autophagy inhibition in CML cell with T315I.

\section{Methods}

Cell viability, cell cycle, cellular senescence, formation of cell clones and apoptosis assay were taken to test the efficiency of medicine. Lentiviral vectors containing shRNA was used to block autophagy and to verify the mechanism of the medicine. Establish tumor models in nude mice, and verify the experimental results in vivo.

\section{Results}

ponatinib and axitinib killed 32Dp210-T315I cells as well as inducing autophagy, which promoted their survival under pressure from TKIs. By inhibiting autophagy, HCQ enhanced the killing effect of ponatinib and axitinib on 32Dp210-T315I cells. In vivo HCQ also enhanced the killing effect of axitinib on 32Dp210T315I cells.

\section{Conclusion}

HCQ combined with ponatinib may be a new strategy for treating CML and ALL that harbor the T315I mutation. Thus, this combination may make it possible to reduce the dose of ponatinib and reduce its side effects without compromising efficacy.

\section{Declarations}

Funding: the research was supported by China postdoctoral science foundation (grant nos. 2018M641865)

Conflicts of interest: The authors declare that they have no conflict of interest.

Compliance with ethical standards

All data and material are availability from the corresponding authors

\section{Introduction}


Generation of the BCR-ABL fusion gene by the reciprocal translocation of chromosomes 9 and 22 in hematopoietic stem cells causes chronic myeloid leukemia (CML) [1]. The BCR-ABL protein has constitutive tyrosine kinase activity and induces oncogenic transformation by activating a cascade of intracellular signaling pathways that lead to uncontrolled cell proliferation [2]. While the introduction of tyrosine kinase inhibitors (TKIs) has revolutionized therapy for $\mathrm{CML}$, primary and secondary resistance due to point mutations in the ABL kinase domain is still great challenges in CML treatment [3-5]. This is especially true for the T315I mutation, which causes a threonine to isoleucine change in the kinase gatekeeper residue, resulting in an altered conformation of the kinase domain that reduces the affinity of BCR-ABL for TKIs [6]. Cells with the BCR-ABL T315I mutation are resistant to almost all TKIs (e.g., imatinib, nilotinib, dasatinib, and bosutinib), therefore therapeutic approaches for CML patients harboring T315I mutations are greatly limited $[7,8]$.

Currently, a third generation TKI, ponatinib that was rationally designed to retain activity against the T315I substitution is used as the first-line therapy for CML with the T315I mutation [9]. However, recent safety data on ponatinib have revealed a dose-dependent increased risk of cardiovascular events including arterial hypertension, serious arterial occlusion, and venous thromboembolism [10-14]. Some clinicians have tried to reduce the dose of ponatinib, but uncertainty about whether this will affect longterm survival outcomes has aroused more concern. How to lower the dose of ponatinib without reducing its efficacy is a great challenge for which combinations with other drugs may be a good option.

Targeting autophagy has been shown to enhance the anti-tumor effects of several drugs [15,16], and the autophagy inhibitor hydroxychloroquine (HCQ) can enhance the anti-CML efficiency of imatinib[17,18]. Whether HCQ is a candidate for combination with ponatinib and the possible underlying molecular mechanisms have not been studied. Additionally, it has been reported that the vascular epidermal growth factor receptor inhibitor axitinib can effectively kill CML cells with the T315I mutation in vitro [19-22]. Whether HCQ can improve the efficacy of axitinib has not been revealed.

In this study, we showed that HCQ could potentiate the efficacy of ponatinib and axitinib on apoptosis and clonality in 32Dp210-T315I cells, but not on their cell cycle progression or senescence. Both ponatinib and axitinib induce autophagy in 32Dp210-T315I cells, which can be blocked by HCQ. We further knocked-down ATG7 using a short hairpin RNA (shRNA) and confirmed that the mechanism of enhanced cell death from HCQ in ponatinib- and axitinib-treated 32Dp210-T315I cells was by inhibiting autophagy. Consistent with the in vitro results, HCQ also enhanced the anti-tumor effects of axitinib on 32Dp210-T315I cells in vivo.

\section{Materials And Methods}

Reagents

Imatinib and HCQ were purchased from Selleck Chemicals (Houston, TX, USA). Axitinib, dasatinib, and ponatinib were from Sigma-Aldrich (St. Louis, MO, USA). All antibodies used in western blot analyses 
were purchased from Cell Signaling Technology (Danvers, MA, USA) with the exception of the anti-P-Crkl antibody, which was from Sigma-Aldrich.

Cell culture

Murine leukemic 32D cells with a wild-type coding sequence BCR-ABL fusion were termed 32Dp210 cells, and 32D cells carrying the BCR-ABL T315I mutation are referred to as 32Dp210-T315I cells. 32Dp210 and 32Dp210-T315I cells were provided by the Department of Hematology at the First Affiliated Hospital of Zhejiang University. All cells were cultured in RPMI-1640 medium containing 10\% fetal bovine serum (FBS) (Gibco, Carlsbad, CA, USA) and $1 \%$ streptomycin at $37^{\circ} \mathrm{C}$ in a humidified atmosphere of $5 \% \mathrm{CO}_{2}$. The 293 T cells were cultured in a high glucose DMEM containing $10 \%$ FBS and $1 \%$ streptomycin. The cells were digested with pancreatic enzymes and centrifuged for passage.

Cell viability assay

Cell viability was tested by the CCK8 assay. The 32Dp210-T315I and 32Dp210 cells were cultured at a density of $4 \times 10^{5}$ cells $/ \mathrm{mL}$ in a 96-well plate (100- $\mu \mathrm{L}$ cell suspension in each well). The wells were divided into different groups ( $n=3$ wells per group), which received different concentrations $(0.1,0.2,0.5,2,5,10$, and $100 \mu \mathrm{M}$ ) of imatinib, dasatinib, ponatinib, or axitinib. Only cell suspension was added in the negative control group and only medium was added in the blank control group. After incubating the cells plus treatments at $37^{\circ} \mathrm{C}$ for $48 \mathrm{~h}, 10 \mu \mathrm{L}$ of CCK8 cell proliferation/toxicity reagents were added to each well and incubated for $4 \mathrm{~h}$. After gently shaking, absorbance values at $450 \mathrm{~nm}$ were detected using a SpectraMax M5 microplate reader (Molecular Devices, San Jose, CA, USA). Each assay was performed three times independently. GraphPad Prism software (GraphPad Software, Inc., San Diego, CA, USA) was used to calculate $\mathrm{IC}_{50}$ values.

\section{Apoptosis assay}

After treating cells with ponatinib $(10 \mathrm{nM})$, axitinib $(100 \mathrm{nM})$, or dasatinib $(1 \mathrm{nM})$ for 24 or $48 \mathrm{~h}$, the cells were collected and washed with PBS. Then the cells were suspended in $500 \mu \mathrm{L}$ of binding buffer and stained with $5 \mu \mathrm{L}$ of Annexin V-FITC and $10 \mu \mathrm{L}$ of 7AAD (Invitrogen) for $30 \mathrm{~min}$ in the dark. Then the cells were examined by flow cytometry (Beckman Coulter, Inc., Miami, FL,USA).

Cell cycle analysis 
Briefly, $1.5-2 \times 10^{6}$ cells were collected, and then added to $1 \mathrm{~mL}$ of propidium iodide staining solution and $10 \mathrm{~mL}$ of cell fixation/membrane solution. After incubating at room temperature for $30 \mathrm{~min}$, cell cycle status was detected with flow cytometry, and cell cycle analysis software was used for analysis.

\section{Cellular senescence assay}

After being treated with TKIs, 32Dp210-T315I and 32Dp210 cells were washed and suspended in $1 \mathrm{~mL}$ of cell fixative solution for 10-20 min. After washing with PBS, the cells were resuspended in $1 \mathrm{~mL}$ of $\beta$ galactosidase staining solution(Cell Signaling Technology, Danvers, MA, USA), and then incubated in a $\mathrm{CO}_{2}$-free incubator at $37^{\circ} \mathrm{C}$ for $14 \mathrm{~h}$. The blue (senescent) cells were observed by light microscopy.

\section{Formation of cell clones}

First, $0.9 \mathrm{~g}$ of methyl cellulose was dissolved in $50 \mathrm{~mL}$ of RPMI- 1640 medium and filtered through a $0.22-$ $\mu \mathrm{m}$ filter to make a sterile 1.8\% methyl cellulose solution. 32D 210-T315I and 32Dp210 cells were resuspended into $5 \times 10^{2}$ cell/mL cell suspensions. The different drugs ( $40 \mathrm{nM}$ axitinib, $4 \mathrm{nM}$ ponatinib, 4 $\mathrm{nM}$ dasatinib, and $4 \mu \mathrm{M} \mathrm{HCQ}$ ) were added into the cell suspensions and mixed. Next, $1 \mathrm{~mL}$ of the single cell suspensions were mixed with $1 \mathrm{~mL}$ of the $1.8 \%$ methyl cellulose solution to make a semisolid medium, which was transferred to 6 -well cell culture plates. After incubation at $37^{\circ} \mathrm{C}$ for $7 \mathrm{~d}$, the number of clones was observed under a microscope. The colony formation rates $(\%)=$ number of clones $\div 500$ $\times 100 \%$.

\section{Protein extraction and western blot analysis}

Cells were lysed in RIPA lysis buffer (Beyotime Institute of Biotechnology, Haimen, China) containing phenylmethanesulfonyl fluoride. Lysates were separated by SDS-polyacrylamide gel electrophoresis, and proteins were transferred onto nitrocellulose membranes. The membranes were blocked in $5 \%$ bovine serum albumen (BBI Life Science, Shanghai, China), and then sequentially incubated with primary and secondary antibodies (Li-Cor Biosciences, Lincoln, NE, USA). The following primary antibodies were used: anti-LC3, anti-ATG7, and anti- $\beta$-actin (Cell Signaling Technology). Immunoreactive bands were visualized using an Odyssey infrared imaging system (Li-Cor Biosciences).

The shRNA preparation and transfection

Lentiviral vectors containing a shRNA against ATG7 or a corresponding control shRNA were synthesized by Gene-Pharma Inc. (Shanghai, China). Lentiviruses were produced in 293T cells by transfecting the 
lentiviral expression vector and packaging vectors (psPAX2 and pMD2.G [Addgene, Cambridge, MA, USA]) using the Attractenen transfection reagent (Qiagen, Hilden, Germany). After enrichment, the lentiviruses were transfected into 32Dp210-T315I and 32Dp210 cells. Transfection efficiency was estimated by evaluating GFP expression. The effects of the shRNAs on autophagy inhibition were tested by western blotting.

Establishing tumor models in nude mice

Twenty-four female nude mice aged 4-5 weeks were raised in the SPF animal center. The feed and drinking water of the mice were subjected to high temperature and pressure sterilization. For inoculation, $4 \times 10^{6} 32 \mathrm{Dp} 210-\mathrm{T} 315 \mathrm{I}$ cells were subcutaneously injected into each mouse. After 2 weeks, when subcutaneous tumors with volumes of approximately $0.5 \mathrm{~cm}^{3}$ had formed, then the mice were randomly divided into 4 four groups. HCQ was dissolved into PBS, and axitinib was dissolved into carboxymethyl cellulose solution for treatment. Mice in the control group were treated with PBS intraperitoneally and carboxymethyl cellulose solution orally. Mice in the HCQ group were treated with $30 \mathrm{mg} / \mathrm{kg} / \mathrm{d}$ HCQ intraperitoneally and carboxymethyl cellulose solution orally. Mice in the axitinib group were treated with PBS intraperitoneally and $20 \mathrm{mg} / \mathrm{kg} / \mathrm{d}$ axitinib carboxymethyl cellulose solution orally. Mice in the combined treatment group were given $30 \mathrm{mg} / \mathrm{kg} / \mathrm{d} \mathrm{HCQ}$ intraperitoneally and $20 \mathrm{mg} / \mathrm{kg} / \mathrm{d}$ axitinib carboxymethyl cellulose solution orally. After treating the mice for $10 \mathrm{~d}$, they were euthanized, and tumors were isolated and weighed.

Statistical analysis

Data were from three independent experiments and expressed as mean \pm SD. All data were analyzed using SPSS 7.0 software with ANOVA or two-tailed Student's t-test. $P<0.05$ was considered statistically significant

\section{Results}

\section{The 32Dp210-T315I cells were resistant to imatinib and dasatinib but sensitive to ponatinib and axitinib.}

The 32Dp210 and 32Dp210-T315I cells stably express BCR-ABL and BCR-ABL T315I proteins, respectively. To test the sensitivity of these cells to different TKIs, we used the CCK-8 cell proliferation/toxicity detection kit to analyze cell viability after 48-h treatments with different TKIs at different concentrations, and calculated the $\mathrm{IC}_{50}$ values. Consistent with previous studies, 32D 210-T315I cells were resistant to imatinib and dasatinib, with $\mathrm{IC}_{50}$ values of $11046 \mathrm{nM}$ and $4876 \mathrm{nM}$ at $48 \mathrm{~h}$, respectively, which are hundreds- and thousands-fold higher than 32Dp210 cells $\left(\mathrm{IC}_{50}\right.$ values of $58.7 \mathrm{nM}$ 
and $1 \mathrm{nM}$ for imatinib and dasatinib, respectively) (Fig. 1a). Both 32Dp210-T315I and 32Dp210 cells were sensitive to ponatinib with similar $\mathrm{IC}_{50}$ values ( $4.8 \mathrm{~nm}$ and $4.3 \mathrm{~nm}$, respectively), indicating the extensive potency of ponatinib in CML treatment (Fig. $1 \mathrm{a}, \mathrm{b}$ ). The $\mathrm{IC}_{50}$ values of axitinib in 32Dp210-T315I and 32Dp210 cells were $43.1 \mathrm{~nm}$ and $124.5 \mathrm{~nm}$, respectively, indicating that 32Dp210 cells were insensitive to axitinib. These results confirmed that 32Dp210-T315I cells were resistant to imatinib and dasatinib, but sensitive to ponatinib and axitinib.

\section{HCQ potentiated the effects of ponatinib and axitinib on 32Dp210-T315I cells.}

\section{- HCQ enhanced ponatinib- and axitinib-induced apoptosis in 32Dp210-T315I cells}

To test whether HCQ enhanced ponatinib- and axitinib-induced apoptosis in 32Dp210-T315I cells, flow cytometry and an annexin V-7AAD apoptosis kit were used to detect apoptosis. Annexin V-positive cells were defined as apoptotic cells. The rates of apoptosis in 32D 210-T315I and 32Dp210 cells treated with ponatinib and axitinib with or without HCQ for $24 \mathrm{~h}$ and $48 \mathrm{~h}$ are shown in Figure 2. Compared with the control group, HCQ did not increase apoptosis levels in 32Dp210-T315I cells $\mathbb{f i g}$.2a,b区. Ponatinib and axitinib induced apoptosis in 32D 210-T315I cells in a time dependent manner; increasing the ponatinib treatment time from $24 \mathrm{~h}$ to $48 \mathrm{~h}$ was associated with an increased apoptosis rate $(24 \mathrm{~h}$ : $15.4 \% \pm 1.4 \% ; 48$ h: $39.7 \% \pm 6.3 \%$ ); similar results were observed in the axitinib group ( $24 \mathrm{~h}: 10.35 \% \pm 1.6 \% ; 48 \mathrm{h:} 42.7 \%$ $\pm 6.9 \%$ )(fig $2 \mathrm{~b}$ ). Combinatorial treatment with HCQ significantly increased ponatinib- and axitinib-induced apoptosis in 32Dp210-T315I cells (fig2a, b). After 24-h treatment, the apoptosis rate in the ponatinib group was $15.4 \% \pm 1.4 \%$, which increased to $55.7 \% \pm 4.5 \%$ in the HCQ + ponatinib group. After 48 -h treatment, HCQ increased the ponatinib-induced apoptosis rate from $39.7 \% \pm 6.3 \%$ to $80.6 \% \pm 4.96 \%$ (fig $2 \mathrm{~b}$ ). Similar results were found in the axitinib and axitinib+HCQ groups. After 24-h and 48-h treatments, HCQ increased the rate of axitinib-induced apoptosis in 32D $210-T 315 \mathrm{I}$ cells from $10.35 \% \pm 1.6 \%$ to $34.2 \%$ $\pm 2.2 \%$ and from $42.7 \% \pm 6.9 \%$ to $67.8 \% \pm 7.7 \%$, respectively (Fig. $2 \mathrm{~b}$ ).

Finally, we detected the rate of apoptosis in 32Dp210 cells. Neither HCQ nor axitinib induced apoptosis in 32Dp210 cells, while both ponatinib and dasatinib could induce apoptosis. HCQ significantly enhanced the rate of apoptosis in 32Dp210 cells treated with ponatinib and dasatinib, but not for those treated with axitinib (Fig. 2c,d).

- HCQ enhanced the inhibitory effect of ponatinib and axitinib on the clonality of 32Dp210-T315I cells.

To test the effect of HCQ combined with either ponatinib or axitinib on cell proliferation, we inoculated the same number of 32Dp210-T315I cells (500/well) onto a semi-solid medium and observed the number of cell colonies after $7 \mathrm{~d}$. As shown in Figure 3 , both ponatinib and axitinib inhibited the clonality of 32Dp210-T315I cells, and the number of colonies was significantly lower than that of the control group 
(fig3a, b). HCQ alone had little effect on the clonality of 32Dp210-T315I cells, but HCQ significantly enhanced the effects of ponatinib and axitinib. After $7 d$, almost no colonies were observed in the HCQ+ponatinib and HCQ+axitinib groups (fig3a, b).

We also performed colony formation assays for 32Dp210 cells. The results showed that HCQ alone had no effect on colony formation in wild-type BCR-ABL expressing cells. Ponatinib inhibited the clonality of 32Dp210 cells, and HCQ further enhanced this effect of ponatinib. Axitinib could not inhibit colony formation in 32Dp210 cells, and HCQ did not modulate axitinib efficacy (fig3b).

\section{- HCQ did not promote ponatinib- or axitinib-induced cell cycle arrest in 32Dp210-T315I cells.}

The induction of cell cycle arrest in CML cells is an important aspect of TKI treatment. We next investigated whether HCQ enhanced the cell cycle arrest induced in 32Dp210-T315I cells by ponatinib and axitinib. To this end, cellular DNA was stained with propidium iodide, and stages of the cell cycle were detected by flow cytometry. Consistent with the active proliferation of tumor cells, most of the 32Dp210-T315I cells in the control group were in S phase $(60.25 \% \pm 5.2 \%)$, some were in G0/G1 $(32.86 \%$ $\pm 4.24 \%$ ), and a few were in G2/M phase (6.89 $\pm 2.1 \%$ ) (Fig. 4a, b). After 48-h treatment with ponatinib or axitinib, a large number of $32 \mathrm{dp} 210-\mathrm{T} 315 \mathrm{I}$ cells were blocked in $\mathrm{G0} / \mathrm{G} 1$ phase $(60.42 \% \pm 3.9 \%$ and $57.45 \%$ $\pm 1.64 \%$, respectively); the number of cells in S phase was also significantly reduced $(36.15 \% \pm 2.9 \%$ and $38.2 \% \pm 4.28 \%$, respectively). Compared with the control group, HCQ alone had no effect on cell cycle progression. Additionally, HCQ did not enhance the cell cycle inhibitory effects of ponatinib or axitinib on 32Dp210-T315I cells; there were no significant differences in the cells treated with or without HCQ (Fig. $4 a, b)$.

When studying 32Dp210 cells, we found that ponatinib significantly blocked cell cycle progression. The proportion of cells in $\mathrm{G} 0 / \mathrm{G} 1$ increased from $31.8 \% \pm 8.86 \%$ to $60.68 \% \pm 5 \%$. Additionally, the ratio of $\mathrm{S}$ phase cells decreased to $17.09 \%$ from $56.03 \% \pm 7.7 \%$. Axitinib had no effect on the cell cycle progression of 32Dp210 cells. HCQ did not enhance the efficacy of either ponatinib or axitinib on 32Dp210 cells (Fig. $4 b)$.

\section{- HCQ did not increase ponatinib- and axitinib-induced senescence in 32Dp210-T315I cells.}

Inducing senescence is the primary mechanism of many anti-tumor drugs. Whether ponatinib and axitinib can induce senescence in 32Dp210-T315I cells, and whether HCQ can further enhance the cell senescence induced by these TKIs have not been evaluated. We assayed for cell senescence by staining with $\beta$-galactosidase. Similar to many other tumor cells, senescent cells account for a low proportion of all 32D 210-T315I and 32Dp210 cells; we found that the rates of senescence in control cells were $1.2 \%$ $\pm 0.9 \%$ and $1.775 \% \pm 0.56 \%$, respectively(Fig5). While ponatinib and axitinib significantly increased the levels of senescent cells, HCQ did not influence their effects. After treatment with ponatinib and axitinib 
for $48 \mathrm{~h}$, the proportions of senescent 32Dp210-T315I cells increased from $1.2 \% \pm 0.9 \%$ to $4.97 \% \pm 1.07 \%$ and $5.6 \% \pm 1.2 \%$, respectively. The proportions of senescent 32D 210-T315I cells treated with ponatinib and axitinib combined with HCQ were $5.9 \% \pm 1.5 \%$ and $5.7 \% \pm 1.03 \%$, respectively. These results confirmed HCQ did not increase ponatinib- and axitinib-induced the senescence in 32Dp210-T315I cells (Fig5) .

Axitinib did not induce senescence in 32Dp210 cells, but ponatinib increased the rate of senescent 32Dp210 cells from $1.78 \% \pm 0.56 \%$ to $12.17 \% \pm 4.56 \%$. Adding HCQ did not significantly alter the proportion of senescent $32 \mathrm{Dp} 210$ cells treated with ponatinib alone $(10.77 \pm 2.21 \%$ and $12.17 \% \pm 4.56 \%$, respectively) (Fig5).

\section{HCQ inhibited ponatinib- and axitinib-induced autophagy in 32Dp210-T315I cells.}

Many studies have revealed that HCQ potentiates the anti-tumor effects of other drugs by inhibiting autophagy. To further understand the mechanism through which HCQ achieves the previously defined effects in 32Dp210-T315I cells, we must answer two questions: (1) do ponatinib and axitinib induce autophagy in 32Dp210-T315I cells; and (2) does HCQ inhibit ponatinib- and axitinib-induced autophagy in 32dp210-T315I cells?

\section{- Ponatinib and axitinib induced autophagy in 32Dp210-T315I cells}

LC3II is specifically expressed on autophagic vacuole membranes, and the quantity of LC3II protein reflects the number of autophagosomes. We tested the expression of LC3II protein in 32Dp210-T315I cells by western blot after 12-h treatment with ponatinib and axitinib. The results showed that compared with the control group, LC3II levels were significantly increased in the ponatinib and axitinib groups (Fig6a). We also labeled LC3 protein with a fluorescent antibody and observed the number of autophagosomes under confocal fluorescence microscopy. This showed that while autophagosomes were rarely seen in 32D 210-T315I cells in the control group, there were a significantly increased number of autophagosomes in the ponatinib group and axitinib groups (Fig. 6b).

The increased levels of LC3II protein expression and number of autophagosomes do not demonstrate induction of autophagy, because autophagy is a dynamic process. Conditions of either autophagy induction or blocking autophagosome degradation will cause LC3II levels to increase. To further identify whether ponatinib and axitinib induced autophagy or blocked autophagic flux, we assayed for LC3II expression in the control group after blocking autophagic flux with HCQ as well as in the ponatinib and axitinib groups. LC3Il levels should be unchanged between the three groups if ponatinib and axitinib block autophagosome degradation, whereas if ponatinib and axitinib induce autophagy, LC3II expression should be significantly higher in the treated cells compared with the control group. The results shown in Figure $6 \mathrm{c}$ demonstrated that LC3II expression was higher in the ponatinib and axitinib groups than in the 
control group. These results confirmed that both ponatinib and axitinib induced autophagy in 32Dp210T315I cells.

We also found that LC3II expression was increased in 32Dp210 cells in the ponatinib group and dasatinib group compared with the control group, but this was not true for the axitinib group (Fig. 6a). After autophagosome degradation was blocked with $\mathrm{HCQ}$, we found that ponatinib and dasatinib could still induce autophagy in 32Dp210 cells, while axitinib could not (Fig. 6c).

\section{- HCQ inhibited ponatinib- and axitinib-induced autophagy in 32Dp210-T315I cells.}

We next addressed whether HCQ could inhibit ponatinib- and axitinib-induced autophagy in 32Dp210T315I cells. ponatinib or axitinib was added with or without HCQ, and then LC3II expression were tested after $6 \mathrm{~h}$. Compared with the ponatinib group, LC3II expression was significantly increased in the ponatinib+HCQ 32Dp210-T315I cells. Similarly, LC3II expression was significantly increased in the axitinib+HCQ group compared with the axitinib group (Fig.7). These results suggested that HCQ inhibited ponatinib- and axitinib-induced autophagy in 32Dp210-T315I cells. We also confirmed HCQ inhibited ponatinib- and dasatinib-induced autophagy in 32Dp210 cells. 8 Fig7区.

\section{Inhibiting autophagy enhances the killing effect of ponatinib and axitinib on 32Dp210-T315I cells.}

\section{- Knocking-down ATG7 inhibited ponatinib- and axitinib- induced autophagy in 32Dp210-T315I cells.}

Thus far, we have confirmed that HCQ inhibits ponatinib- and axitinib-induced autophagy, but it remained unclear whether inhibiting autophagy was the mechanism by which HCQ enhanced the killing effect ponatinib and axitinib on 32Dp210-T315I cells. ATG7 is an important autophagy regulator, and it has been reported that knocking down ATG7 can specifically block autophagy. We knocked down ATG7 using a shRNA to inhibit autophagy, and then analyzed whether inhibiting autophagy enhanced the killing effect of ponatinib and axitinib on 32Dp210-T315I cells.

We designed and synthesized a lentiviral plasmid vector with shRNA-ATG7 and GFP to knockdown ATG7 protein expression in 32Dp210-T315I and 32Dp210 cells. Five days after lentiviral infection, the proportion of GFP-positive cells was detected by flow cytometry, and the results showed that the proportion of GFP positive cells was $>90 \%$ (Fig. 8a). Cells were also collected to detect ATG7 protein expression by western blot. This revealed that shRNA-ATG7-1 and shRNA-ATG7-2 significantly inhibited ATG7 protein expression compared with the control shRNA (Fig. 8b ). After knocking-down the expression of ATG7 in 32Dp210-T315I cells, we tested whether ponatinib and axitinib could still induce autophagy. As seen in Figure8b, after ponatinib and axitinib treatment, LC3II expression was much higher in the control group than in the ATG7-knockdown groups, with almost undetectable LC3II levels in ATG7knockdown cells. This result showed that knocking down ATG7 blocked ponatinib- and axitinib-induced 
autophagy in 32Dp210-T315I cells. Similar results were seen in 32Dp210 cells (Fig.8b). After treatment with ponatinib, LC3II expression was lower in ATG7-knockdown 32Dp210 cells compared with control cells (Fig.8b). Thus, knocking down ATG7 blocked ponatinib-induced autophagy in 32Dp210 cells.

\section{- Knocking down ATG7 was nontoxic to 32Dp210-T315I and 32Dp210 cells}

We next examined the effects of knocking down ATG7 on apoptosis, cell cycle progression, and colony formation. Annexin $\mathrm{V}$ and 7AAD were used to detect apoptosis $15 \mathrm{~d}$ after lentiviral infection. Annexin $\mathrm{V}$ positive celles were thought apoptosis. As shown in Figur9a, the apoptosis rate in ATG7-knockdown cells did not increase compared with controls. The cell cycle analysis showed that there was no significant difference in cell cycle distribution between the ATG7-knockdown group and the control group, with most cells in S and G1 phase, and few in G2/M phase (Fig. 9b). We also found that ATG7 knockdown had no effect on colony formation in 32Dp210-T315I and 32Dp210 cells. After in vitro culture for $7 \mathrm{~d}$, the colony formation rates in the control group were $89.8 \pm 14.2 \%$, and $86.9 \% \pm 17.4 \%$ and $90.2 \% \pm 18 \%$ in ATG7knockdown 32Dp210-T315I cells (Fig.9c). In 32Dp210 cells, the colony formation rates of control and ATG7 knockout groups were $91.8 \pm 10.4 \%, 88.8 \pm 13.1 \%$ and $87.4 \pm 9.6 \%$, respectively (Fig $9 \mathrm{c}$ ). Together, these results suggested that ATG7 knockdown was nontoxic to 32Dp210-T315I and 32Dp210 cells.

\section{- ATG7 knockdown enhanced ponatinib- and axitinib-induced apoptosis in 32Dp210-T315I cells.}

We next addressed whether inhibiting autophagy by knocking-down ATG7 enhanced ponatinib- and axitinib-induced apoptosis in 32Dp210-T315I cells. After treatment with ponatinib and axitinib for $48 \mathrm{~h}$, we assayed for apoptosis in ATG7-knockdown 32Dp210-T315I cells. Compared with the control group, ATG7-knockdown 32Dp210-T315I cells were more sensitive to ponatinib and axitinib (Fig10a, b). The apoptosis rates in the control and ATG7-knockdown groups were $32.9 \% \pm 7.4 \%, 68.2 \% \pm 8.2 \%$, and $59.4 \%$ $\pm 7.3 \%$, respectively, after ponatinib treatment; the apoptosis rates were $45.8 \% \pm 7.96 \%, 77.0 \% \pm 6.3 \%$, and 71.9\% $\pm 9.1 \%$, respectively, after axitinib treatment (Fig10a,b). Our results also showed that ATG7 knockdown increased the sensitivity of 32Dp210 cells to ponatinib and dasatinib, but did not increase the sensitivity of 32Dp210 cells to axitinib (Fig. 10b).

\section{- ATG7 knockdown did not influence the ponatinib- and axitinib-induced cell cycle arrest of 32Dp210- T315I cells.}

To test whether inhibiting autophagy promoted ponatinib- and axitinib-induced cell cycle arrest in 32Dp210-T315I cells, cell cycle distributions were evaluated in ATG7-knockdown and control 32Dp210T315I cells after treatment with these drugs for $48 \mathrm{~h}$. Both ponatinib and axitinib had similar effects on the ATG7-knockdown and control groups; most cells were blocked in G0/G1 phase, and there were few 
cells in S phase and in G2/M phase (Fig. 11a, b). There were no statistical difference between ATG7knockdown group and control groups. After ponatinib, dasatinib and axitinib treatment, the cell cycle distributions of ATG7-knockdown and control 32dp210 cells were similar (Fig. 11 b).

\section{HCQ enhanced the killing effect of axitinib on 32Dp210-T315I cells in vivo.}

Currently, studys on the toxicity of axitinib to BCR-ABL expressing cells with the T315I mutation were limited to only in vitro experiments. Therefore, we next tested whether axitinib could kill cells with the T315I mutation and whether HCQ could enhance this activity using an in vivo model. To answer these questions we established a model of subcutaneous neoplasia with 32Dp210-T315I cells in nude mice.

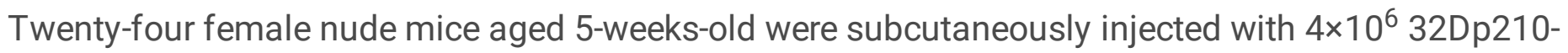
T315I cells .After 2 weeks, tumors had formed under the skin, and the volumes were $0.49-0.52 \mathrm{~cm}^{3}$ (Fig. $12 a, b)$. Nude mice were randomly divided into four groups with six mice in each group: the control group; HCQ group; axitinib group; and HCQ+axitinib group. There was no statistical difference in tumor volume among groups before treatment (Fig. 12b). Ten days after treatment, the mice were sacrificed, and tumors were removed to compare weights. The mean tumor weights were similar in the HCQ and control groups, and were the highest among the four groups. The mean tumor weight in the HCQ+axitinib group was the lowest, while that in the group treated with axitinib alone was the second lowest (Fig 12c). These results confirmed that axitinib could kill 32Dp210-T315I cells in vivo and were consistent with the in vitro results that showed HCQ could further enhance the anti-tumor effects of axitinib.

\section{Discussion}

Ponatinib is now the first-line therapy for CML with the T315I mutation; however, reducing the side effects of ponatinib without reducing its efficacy is a great challenge $[9,23]$. Amino acid 315 is normally a threonine that serves as the "gatekeeper" residue for the BCR-ABL kinase, and mutations at this site often seriously affect the binding of TKIs with the kinase, which is the primary cause of multi-drug resistance $[23,24]$. The substitution of threonine with isoleucine at this position gives rise to the T315I mutation, which is resistant to first and second generation TKIs. For a long time, the prognosis of CML patients with T315I mutations was very poor due to the lack of an effective drug [25]. The third generation TKI ponatinib was developed on the basis of molecular structure and can overcome steric hindrance to bind to BCR-ABL T315I protein and effectively inhibit its kinase activity. Ponatinib is potent in the treatment of CML with the T315I mutation, regardless of whether patients are in the chronic, advanced, or blastic phases[23]. A retrospective study showed that ponatinib in chronic phase-CML with the T315I mutation was associated with significantly longer overall survival than stem cell transplantation [26]. In patients with advanced CML, ponatinib can be used as a bridge to allogeneic stem cell transplantation and can induce a secondary chronic phase [27]. In non-transplantable patients at high risk and in relapsed patients after transplantation, ponatinib significantly improves long-term survival [28]. Our study also confirmed that 32Dp210-T315I cells were sensitive to ponatinib but resistant to imatinib and dasatinib. 
Ponatinib is the first-line therapy for CML and ALL harboring the T315I mutation; however the potential risk and toxicity of ponatinib treatment must be taken seriously. Several studies have revealed a dosedependent increase in risk of serious cardiovascular events, including severe arterial hypertension, serious arterial occlusive events (AOEs), and venous thromboembolic events (VTEs) [29-31]. The Phase II PACE trial showed after 5 years of follow-up, the cumulative incidence of AOEs in the chronic phase-CML population for whom the initial dose of ponatinib was $45 \mathrm{mg}$ daily was as high as $31 \%$, with severe AOEs accounting for $26 \%$. Except for commonly recognized cardiovascular risk factors (hypertension, hypercholesterolemia, diabetes, and obesity), AOEs were ponatinib dose-related [32]. Thus reducing ponatinib doses without reducing its efficacy is crucial, for which combinatorial treatment with other drugs is a good option. In the past few years, a large number of clinical trials have confirmed that targeting autophagy with HCQ can enhance the efficacy of both radiotherapy and chemotherapy in various hematological diseases and solid tumors [33,34]. Our study revealed that HCQ significantly enhanced the efficacy of ponatinib on 32Dp210-T315I cells with regards to apoptosis and colony formation, while it did not affect cell cycle arrest or senescence. These data suggested that $\mathrm{HCQ}+$ ponatinib may be a new strategy for treating CML with the T315I mutation that makes it is possible to reduce the ponatinib dose and its side effects without compromising efficacy.

Axitinib is also potential drug for treating CML and ALL with the T315I mutation [35]. Axitinib is a vascular epidermal growth factor receptor inhibitor that also has TKI activity. Two in vitro studies have confirmed that axitinib specifically binds to the BCR-ABL-T315I fusion protein and inhibits kinase activity. However, it is noteworthy that axitinib does not bind to wide-type BCR-ABL protein and has no therapeutic effect on CML and ALL without the T315I mutation [35]. After toxicity was detected using the CCK8 kit, our study confirmed that axitinib effectively killed 32Dp210-T315I cells, but did not show toxicity towards 32Dp210 cells with the wild-type BCR-ABL fusion protein (Fig. 1.2). Meanwhile HCQ enhanced the killing effects of axitinib on 32Dp210-T315I cells but not on 32Dp210 cells. Further experiments in nude mice confirmed these results in vivo, which imply HCQ combined with axitinib also is potentinal therapy for CML with T315I mutation.

Similar to wild-type BCR-ABL protein, mutant BCR-ABL-T315I protein inhibits autophagy in CML cells. As a tyrosine kinase the BCR-ABL fusion protein can activate a variety of intracellular signaling pathways, among which, activation of the PI3K/AKT pathway can not only promote excessive proliferation of malignant cells, but can also inhibit autophagy. The mTOR is an important autophagy regulator that inhibits autophagy by blocking formation of the ULK1/2-ATG13-FIP2100 complex [36]. BCR-ABL protein can activate the PI3K/AKT pathway, upregulate ATF5 expression, and active mTOR, thus inhibiting autophagy [37]. Targeting BCR-ABL with imatinib simultaneously induces apoptosis and autophagy in CML cells [38,39]. Crkl protein is a substrate of the fusion kinase, and levels of phosphorylated Crkl can reflect the kinase activity of the fusion protein. Consistent with previous data, our study have confirmed that ponatinib and dasatinib induce autophagy while inhibiting the kinase activity of BCR-ABL protein in 32Dp210 cells (Fig6). Furthermore, after treatment with ponatinib or axitinib for $12 \mathrm{~h}$, phosphorylated Crkl levels were decreased in 32Dp210-T315I cells, which implied the inhibition BCR-ABL-T315I kinase activity. Meanwhile, LC3II expression was increased, as were the numbers of autophagosomes (Fig. 6). As the 
negative control dasatinib did not inhibit the kinase activity of the BCR-ABL-T315I protein, LC3II expression $\nabla$ and the number of autophagosomes were unchanged. These results suggested that the molecular conformation of the BCR-ABL-T315I fusion protein was different from that of wild-type BCRABL protein, but it can also inhibit autophagy in 32Dp210-T315I cells. Thus, targeting the fusion protein with ponatinib and axitinib can not only induce apoptosis in 32Dp210-T315I cells, but can also induce autophagy. The induction of autophagy is related to the inhibited kinase activity of BCR-ABL-T315I by ponatinib and axitinib in 32Dp210-T315I cells, but whether the PI3K/AKI/ATF5 pathway is the key pathway for autophagy inhibition remains to be further studied.

Targeting autophagy is the primary activity of HCQ investigated in our research. HCQ is a multi-functional drug that inhibits antigen delivery, prostaglandin and cytokine synthesis, regulates toll-like receptors, and affects serum metalloproteinase levels $[40,41]$. As a classic anti-malarial and anti-rheumatic drug, HCQ has been used in clinical settings for over 70 years. Recently HCQ has attracted much attention as an autophagy inhibitor. Through inhibiting the fusion of autophagosomes with lysosomes, HCQ effectively blocks autophagosome flux and causes the aggregation of autophagosomes in cells[42]. After confirmed HCQ can potentiat the effects of ponatinib and axitinib on 32Dp210-T315I cells, Our work showed that HCQ could effectively block ponatinib- and axitinib-induced autophagy in 32Dp210-T315I cells (Fig. 1.4). Furthermore inhibiting autophagy with a shRNA targeting ATG7 also enhanced the apoptosis induced by ponatinib and axitinib in 32Dp210-T315I cells. These results proved that HCQ enhanced the killing effect of ponatinib and axitinib in 32Dp210-T315I cells by inhibiting autophagy.

Autophagy allows cell survival in unfavorable conditions; thus, inhibiting autophagy has become a hotspot for anti-tumor therapy. Our study confirmed that ponatinib and axitinib induce autophagy in cells with the T315I mutation; thus, HCQ enhanced the killing effects of ponatinib and axitinib by inhibiting autophagy. However, the mechanism by which autophagy promoted cell survival under TKI treatment is unclear. Activation of apoptosis-related proteins by cytochrome $\mathrm{C}$, which is released from mitochondria, is the key step to initiate apoptosis. Some researchers have suggested that autophagosomes engulf damaged mitochondria, blocking the release of cytochrome $\mathrm{C}$ from mitochondria, and thus blocking the major apoptotic pathway [43, 44]. Our study suggested that by inducing autophagy, 32Dp210-T315I cells evaded the apoptosis induced by ponatinib and axitinib to some extent, but didnot evade the cell cycle arrest and senescence induced by ponatinib and axitinib. Further research focused on apoptosis-related proteins that are regulated by autophagy will help reveal the key mechanism of how autophagy promotes survival.

In conclusion, ponatinib and axitinib killed 32Dp210-T315I cells as well as inducing autophagy, which promoted their survival under pressure from TKIs. By inhibiting autophagy, HCQ enhanced the killing effect of ponatinib and axitinib on 32Dp210-T315I cells. This suggested that HCQ combined with ponatinib may be a new strategy for treating CML and ALL that harbor the T315I mutation. Thus, this combination may make it possible to reduce the dose of ponatinib and reduce its side effects without compromising efficacy. 


\section{References}

1. Hu Y, Wu Z, Luo Y, Shi J, Yu J, Pu C, Liang Z, Wei G, Cui Q, Sun J, Jiang J, Xie J, Tan Y, Ni W, Tu J, Wang J, Jin A, Zhang H, Cai Z, Xiao L, Huang H (2017) Potent Anti-leukemia Activities of Chimeric Antigen Receptor-Modified T Cells against CD19 in Chinese Patients with Relapsed/Refractory Acute Lymphocytic Leukemia. Clin Cancer Res 23: 3297-3306 DOI 10.1158/1078-0432.CCR-16-1799

2. Chong EA, Melenhorst JJ, Lacey SF, Ambrose DE, Gonzalez V, Levine BL, June CH, Schuster SJ (2017) PD-1 blockade modulates chimeric antigen receptor (CAR)-modified T cells: refueling the CAR. Blood 129: 1039-1041 DOI 10.1182/blood-2016-09-738245

3. Bonneville M, O'Brien RL, Born WK (2010) Gammadelta T cell effector functions: a blend of innate programming and acquired plasticity. Nat Rev Immunol 10: 467-478 DOI 10.1038/nri2781

4. Vantourout P, Hayday A (2013) Six-of-the-best: unique contributions of gammadelta $T$ cells to immunology. Nat Rev Immunol 13: 88-100 DOI 10.1038/nri3384

5. Castella B, Riganti C, Fiore F, Pantaleoni F, Canepari ME, Peola S, Foglietta M, Palumbo A, Bosia A, Coscia M, Boccadoro M, Massaia M (2011) Immune modulation by zoledronic acid in human myeloma: an advantageous cross-talk between Vgamma9Vdelta2 T cells, alphabeta CD8+ T cells, regulatory T cells, and dendritic cells. J Immunol 187: 1578-1590 DOI 10.4049/jimmunol.1002514

6. Nicolini FE, Basak GW, Kim DW, Olavarria E, Pinilla-lbarz J, Apperley JF, Hughes T, Niederwieser D, Mauro MJ, Chuah C, Hochhaus A, Martinelli G, DerSarkissian M, Duh MS, McGarry LJ, Kantarjian HM, Cortes JE (2017) Overall survival with ponatinib versus allogeneic stem cell transplantation in Philadelphia chromosome-positive leukemias with the T315I mutation. Cancer 123: 2875-2880 DOI 10.1002/cncr.30558

7. Cortes JE, Kim DW, Pinilla-Ibarz J, le Coutre PD, Paquette R, Chuah C, Nicolini FE, Apperley JF, Khoury HJ, Talpaz M, DeAngelo DJ, Abruzzese E, Rea D, Baccarani M, Muller MC, Gambacorti-Passerini C, Lustgarten S, Rivera VM, Haluska FG, Guilhot F, Deininger MW, Hochhaus A, Hughes TP, Shah NP, Kantarjian HM (2018) Ponatinib efficacy and safety in Philadelphia chromosome-positive leukemia: final 5-year results of the phase 2 PACE trial. Blood 132: 393-404 DOI 10.1182/blood-2016-09739086

8. Khoury HJ, Kukreja M, Goldman JM, Wang T, Halter J, Arora M, Gupta V, Rizzieri DA, George B, Keating A, Gale RP, Marks DI, McCarthy PL, Woolfrey A, Szer J, Giralt SA, Maziarz RT, Cortes J, Horowitz MM, Lee SJ (2012) Prognostic factors for outcomes in allogeneic transplantation for CML in the imatinib era: a CIBMTR analysis. Bone Marrow Transplant 47: 810-816 DOI 10.1038/bmt.2011.194

9. Cortes JE, Kim DW, Pinilla-lbarz J, le Coutre PD, Paquette R, Chuah C, Nicolini FE, Apperley JF, Khoury HJ, Talpaz M, DeAngelo DJ, Abruzzese E, Rea D, Baccarani M, Muller MC, Gambacorti-Passerini C, Lustgarten S, Rivera VM, Haluska FG, Guilhot F, Deininger MW, Hochhaus A, Hughes TP, Shah NP, Kantarjian HM (2018) Ponatinib efficacy and safety in Philadelphia chromosome-positive leukemia: final 5-year results of the phase 2 PACE trial. Blood 132: 393-404 DOI 10.1182/blood-2016-09739086 
10. Moslehi JJ, Deininger M (2015) Tyrosine Kinase Inhibitor-Associated Cardiovascular Toxicity in Chronic Myeloid Leukemia. J Clin Oncol 33: 4210-4218 DOI 10.1200/JC0.2015.62.4718

11. Valent $P$, Hadzijusufovic E, Schernthaner GH, Wolf D, Rea D, le Coutre P (2015) Vascular safety issues in CML patients treated with BCR/ABL1 kinase inhibitors. Blood 125: 901-906 DOI 10.1182/blood2014-09-594432

12. (2014) Ariad suspends ponatinib sales. Cancer Discov 4: 6-7 DOI 10.1158/2159-8290.CD-NB2013163

13. Roth AJ (2014) Reversing Halt, FDA reauthorizes sale of ponatinib. Am J Manag Care 20: E11

14. Cortes JE, Kim DW, Pinilla-Ibarz J, le Coutre P, Paquette R, Chuah C, Nicolini FE, Apperley JF, Khoury HJ, Talpaz M, DiPersio J, DeAngelo DJ, Abruzzese E, Rea D, Baccarani M, Muller MC, GambacortiPasserini C, Wong S, Lustgarten S, Rivera VM, Clackson T, Turner CD, Haluska FG, Guilhot F, Deininger MW, Hochhaus A, Hughes T, Goldman JM, Shah NP, Kantarjian H (2013) A phase 2 trial of ponatinib in Philadelphia chromosome-positive leukemias. N Engl J Med 369: 1783-1796 DOI 10.1056/NEJMoa1306494

15. Townsend KN, Hughson LR, Schlie K, Poon VI, Westerback A, Lum JJ (2012) Autophagy inhibition in cancer therapy: metabolic considerations for antitumor immunity. Immunol Rev 249: 176-194 DOI 10.1111/j.1600-065X.2012.01141.x

16. Vogl DT, Stadtmauer EA, Tan KS, Heitjan DF, Davis LE, Pontiggia L, Rangwala R, Piao S, Chang YC, Scott EC, Paul TM, Nichols CW, Porter DL, Kaplan J, Mallon G, Bradner JE, Amaravadi RK (2014) Combined autophagy and proteasome inhibition: a phase 1 trial of hydroxychloroquine and bortezomib in patients with relapsed/refractory myeloma. Autophagy 10: 1380-1390 DOI 10.4161/auto.29264

17. Sheng Z, Ma L, Sun JE, Zhu LJ, Green MR (2011) BCR-ABL suppresses autophagy through ATF5mediated regulation of mTOR transcription. Blood 118: 2840-2848 DOI 10.1182/blood-2010-12322537

18. Calabretta B, Salomoni P (2012) Suppression of autophagy by BCR/ABL. Front Biosci (Schol Ed) 4: 453-460 DOI 10.2741/278

19. Pemovska T, Johnson E, Kontro M, Repasky GA, Chen J, Wells P, Cronin CN, McTigue M, Kallioniemi O, Porkka K, Murray BW, Wennerberg K (2015) Axitinib effectively inhibits BCR-ABL1(T315I) with a distinct binding conformation. Nature 519: 102-105 DOI 10.1038/nature14119

20. Zabriskie MS, Eide CA, Yan D, Vellore NA, Pomicter AD, Savage SL, Druker BJ, Deininger MW, O'Hare T (2016) Extreme mutational selectivity of axitinib limits its potential use as a targeted therapeutic for BCR-ABL1-positive leukemia. Leukemia 30: 1418-1421 DOI 10.1038/leu.2015.318

21. Mizushima N (2007) Autophagy: process and function. Genes Dev 21: 2861-2873 DOI $10.1101 /$ gad. 1599207

22. Sheng Z, Ma L, Sun JE, Zhu LJ, Green MR (2011) BCR-ABL suppresses autophagy through ATF5mediated regulation of mTOR transcription. Blood 118: 2840-2848 DOI 10.1182/blood-2010-12322537 
23. O'Hare T, Eide CA, Deininger MW (2007) Bcr-Abl kinase domain mutations, drug resistance, and the road to a cure for chronic myeloid leukemia. Blood 110: 2242-2249 DOI 10.1182/blood-2007-03066936

24. Raaijmakers MH (2007) ATP-binding-cassette transporters in hematopoietic stem cells and their utility as therapeutical targets in acute and chronic myeloid leukemia. Leukemia 21: 2094-2102 DOI $10.1038 /$ sj.leu.2404859

25. Jabbour E, Cortes JE, Giles FJ, O'Brien S, Kantarjian HM (2007) Current and emerging treatment options in chronic myeloid leukemia. Cancer 109: 2171-2181 DOI 10.1002/cncr.22661

26. Nicolini FE, Basak GW, Kim DW, Olavarria E, Pinilla-lbarz J, Apperley JF, Hughes T, Niederwieser D, Mauro MJ, Chuah C, Hochhaus A, Martinelli G, DerSarkissian M, Duh MS, McGarry LJ, Kantarjian HM, Cortes JE (2017) Overall survival with ponatinib versus allogeneic stem cell transplantation in Philadelphia chromosome-positive leukemias with the T315I mutation. Cancer 123: 2875-2880 DOI 10.1002/cncr.30558

27. Cortes JE, Kim DW, Pinilla-Ibarz J, le Coutre PD, Paquette R, Chuah C, Nicolini FE, Apperley JF, Khoury HJ, Talpaz M, DeAngelo DJ, Abruzzese E, Rea D, Baccarani M, Muller MC, Gambacorti-Passerini C, Lustgarten S, Rivera VM, Haluska FG, Guilhot F, Deininger MW, Hochhaus A, Hughes TP, Shah NP, Kantarjian HM (2018) Ponatinib efficacy and safety in Philadelphia chromosome-positive leukemia: final 5-year results of the phase 2 PACE trial. Blood 132: 393-404 DOI 10.1182/blood-2016-09739086

28. Khoury HJ, Kukreja M, Goldman JM, Wang T, Halter J, Arora M, Gupta V, Rizzieri DA, George B, Keating A, Gale RP, Marks DI, McCarthy PL, Woolfrey A, Szer J, Giralt SA, Maziarz RT, Cortes J, Horowitz MM, Lee SJ (2012) Prognostic factors for outcomes in allogeneic transplantation for CML in the imatinib era: a CIBMTR analysis. Bone Marrow Transplant 47: 810-816 DOI 10.1038/bmt.2011.194

29. Cortes JE, Kim DW, Pinilla-Ibarz J, le Coutre P, Paquette R, Chuah C, Nicolini FE, Apperley JF, Khoury HJ, Talpaz M, DiPersio J, DeAngelo DJ, Abruzzese E, Rea D, Baccarani M, Muller MC, GambacortiPasserini C, Wong S, Lustgarten S, Rivera VM, Clackson T, Turner CD, Haluska FG, Guilhot F, Deininger MW, Hochhaus A, Hughes T, Goldman JM, Shah NP, Kantarjian H (2013) A phase 2 trial of ponatinib in Philadelphia chromosome-positive leukemias. N Engl J Med 369: 1783-1796 DOI 10.1056/NEJMoa1306494

30. Moslehi JJ, Deininger M (2015) Tyrosine Kinase Inhibitor-Associated Cardiovascular Toxicity in Chronic Myeloid Leukemia. J Clin Oncol 33: 4210-4218 DOI 10.1200/JC0.2015.62.4718

31. Valent $P$, Hadzijusufovic $E$, Schernthaner $G H$, Wolf $D$, Rea $D$, le Coutre $P(2015)$ Vascular safety issues in CML patients treated with BCR/ABL1 kinase inhibitors. Blood 125: 901-906 DOI 10.1182/blood2014-09-594432

32. Cortes JE, Kim DW, Pinilla-Ibarz J, le Coutre PD, Paquette R, Chuah C, Nicolini FE, Apperley JF, Khoury HJ, Talpaz M, DeAngelo DJ, Abruzzese E, Rea D, Baccarani M, Muller MC, Gambacorti-Passerini C, Lustgarten S, Rivera VM, Haluska FG, Guilhot F, Deininger MW, Hochhaus A, Hughes TP, Shah NP, 
Kantarjian HM (2018) Ponatinib efficacy and safety in Philadelphia chromosome-positive leukemia: final 5-year results of the phase 2 PACE trial. Blood 132: 393-404 DOI 10.1182/blood-2016-09739086

33. Abedin MJ, Wang D, McDonnell MA, Lehmann U, Kelekar A (2007) Autophagy delays apoptotic death in breast cancer cells following DNA damage. Cell Death Differ 14: 500-510 DOI 10.1038/sj.cdd. 4402039

34. Townsend KN, Hughson LR, Schlie K, Poon VI, Westerback A, Lum JJ (2012) Autophagy inhibition in cancer therapy: metabolic considerations for antitumor immunity. Immunol Rev 249: 176-194 DOI 10.1111/j.1600-065X.2012.01141.x

35. Pemovska T, Johnson E, Kontro M, Repasky GA, Chen J, Wells P, Cronin CN, McTigue M, Kallioniemi O, Porkka K, Murray BW, Wennerberg K (2015) Axitinib effectively inhibits BCR-ABL1(T315I) with a distinct binding conformation. Nature 519: 102-105 DOI 10.1038/nature14119

36. Jung CH, Jun CB, Ro SH, Kim YM, Otto NM, Cao J, Kundu M, Kim DH (2009) ULK-Atg13-FIP200 complexes mediate mTOR signaling to the autophagy machinery. Mol Biol Cell 20: 1992-2003 DOI $10.1091 / \mathrm{mbc} . \mathrm{e} 08-12-1249$

37. Sheng Z, Ma L, Sun JE, Zhu LJ, Green MR (2011) BCR-ABL suppresses autophagy through ATF5mediated regulation of mTOR transcription. Blood 118: 2840-2848 DOI 10.1182/blood-2010-12322537

38. Helgason GV, Karvela M, Holyoake TL (2011) Kill one bird with two stones: potential efficacy of BCRABL and autophagy inhibition in CML. Blood 118: 2035-2043 DOI 10.1182/blood-2011-01-330621

39. Elzinga BM, Nyhan MJ, Crowley LC, O'Donovan TR, Cahill MR, McKenna SL (2013) Induction of autophagy by Imatinib sequesters Bcr-Abl in autophagosomes and down-regulates Bcr-Abl protein. Am J Hematol 88: 455-462 DOI 10.1002/ajh.23428

40. Lesiak A, Narbutt J, Sysa-Jedrzejowska A, Lukamowicz J, McCauliffe DP, Wozniacka A (2010) Effect of chloroquine phosphate treatment on serum MMP-9 and TIMP-1 levels in patients with systemic lupus erythematosus. Lupus 19: 683-688 DOI 10.1177/0961203309356455

41. Devaux CA, Rolain JM, Colson P, Raoult D (2020) New insights on the antiviral effects of chloroquine against coronavirus: what to expect for COVID-19? Int J Antimicrob Agents 55: 105938 DOI 10.1016/j.jjantimicag.2020.105938

42. Stadtmauer EA, Tan KS, Heitjan DF, Davis LE, Pontiggia L, Rangwala R, Piao S, Chang YC, Scott EC, Paul TM, Nichols CW, Porter DL, Kaplan J, Mallon G, Bradner JE, Amaravadi RK (2014) Combined autophagy and proteasome inhibition: a phase 1 trial of hydroxychloroquine and bortezomib in patients with relapsed/refractory myeloma. Autophagy 10: 1380-1390 DOI 10.4161/auto.29264

43. Berger Z, Ravikumar B, Menzies FM, Oroz LG, Underwood BR, Pangalos MN, Schmitt I, Wullner U, Evert BO, O'Kane CJ, Rubinsztein DC (2006) Rapamycin alleviates toxicity of different aggregateprone proteins. Hum Mol Genet 15: 433-442 DOI 10.1093/hmg/ddi458

44. Colell A, Ricci JE, Tait S, Milasta S, Maurer U, Bouchier-Hayes L, Fitzgerald P, Guio-Carrion A, Waterhouse NJ, Li CW, Mari B, Barbry P, Newmeyer DD, Beere HM, Green DR (2007) GAPDH and 
autophagy preserve survival after apoptotic cytochrome $\mathrm{c}$ release in the absence of caspase activation. Cell 129: 983-997 DOI 10.1016/j.cell.2007.03.045

Figures

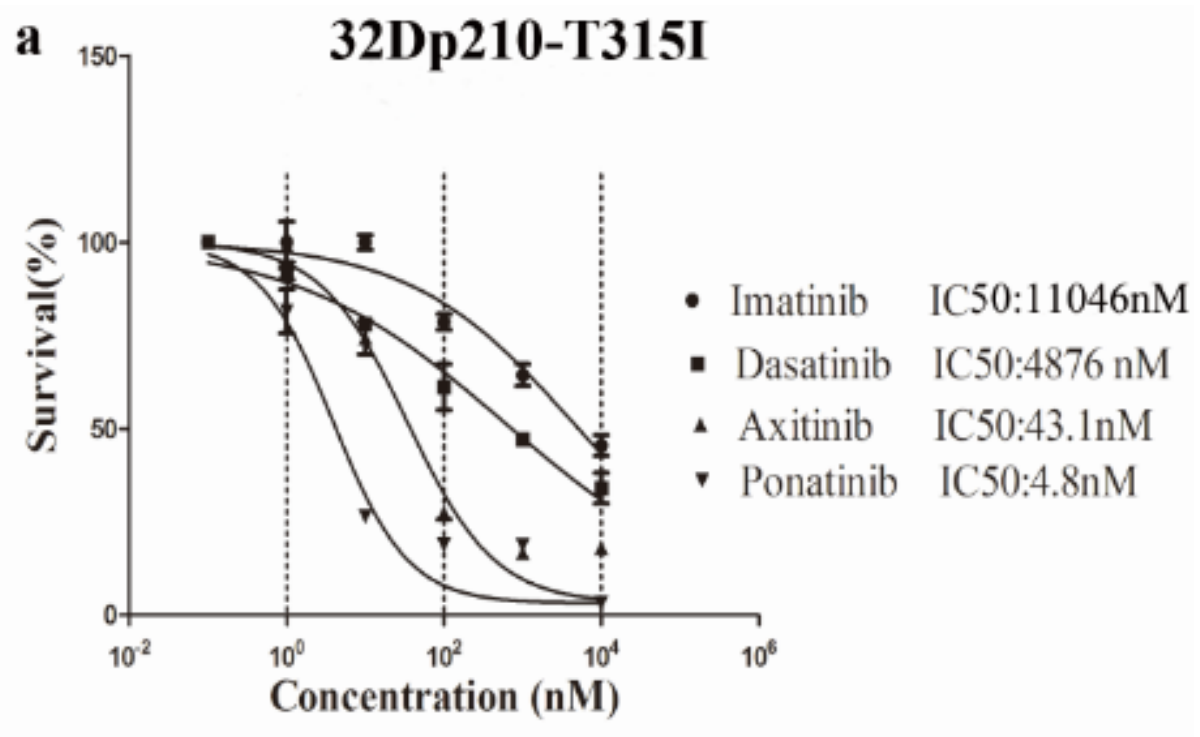

b $\quad 32 D p 210$

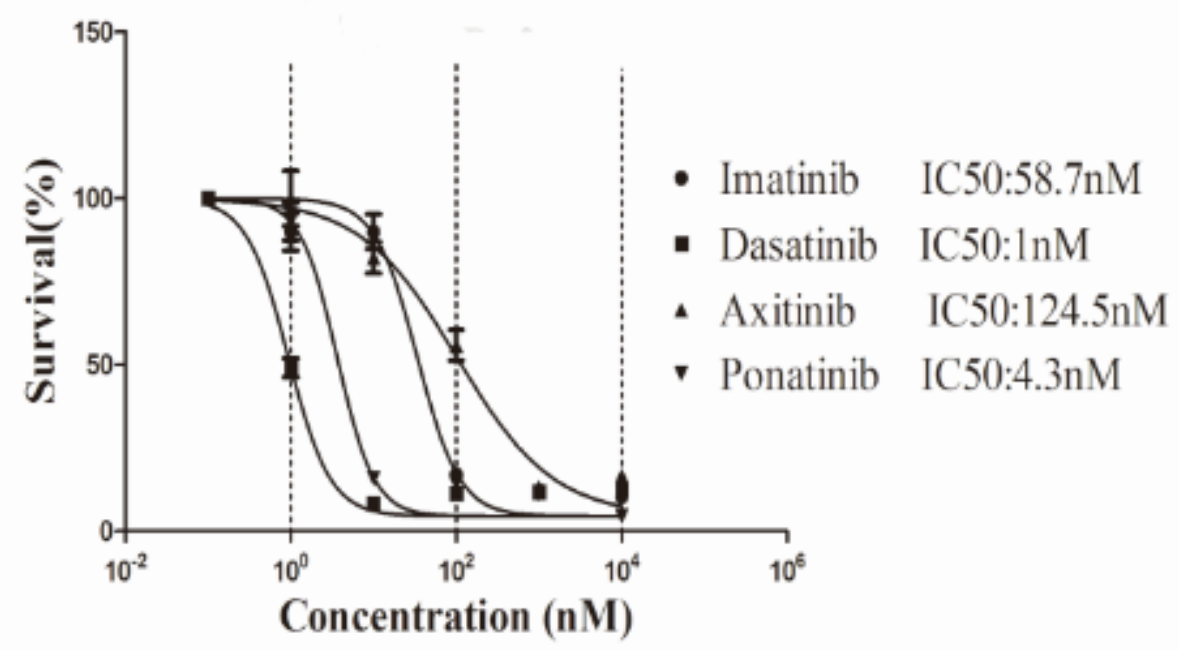

Figure 1

The sensitivity of 32Dp210-T315I and 32Dp210 to TKIs. a and b After 48-h treated with TKIs (imatinib dasatinib ponatinib and axitinib) the survival of 32Dp210-T315I cells and 32Dp210 cells. 
b

32Dp210-T315I

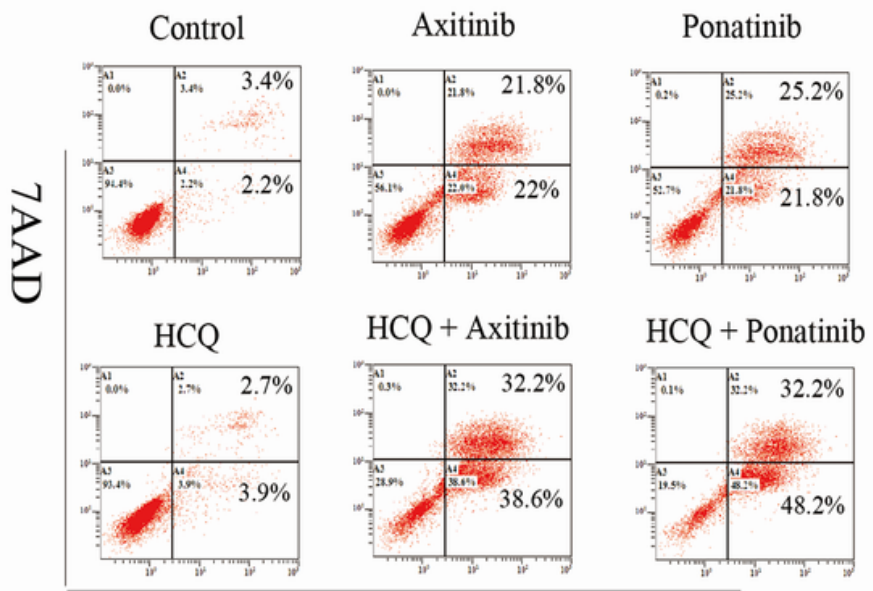

Annexin V -PE

c

32Dp210

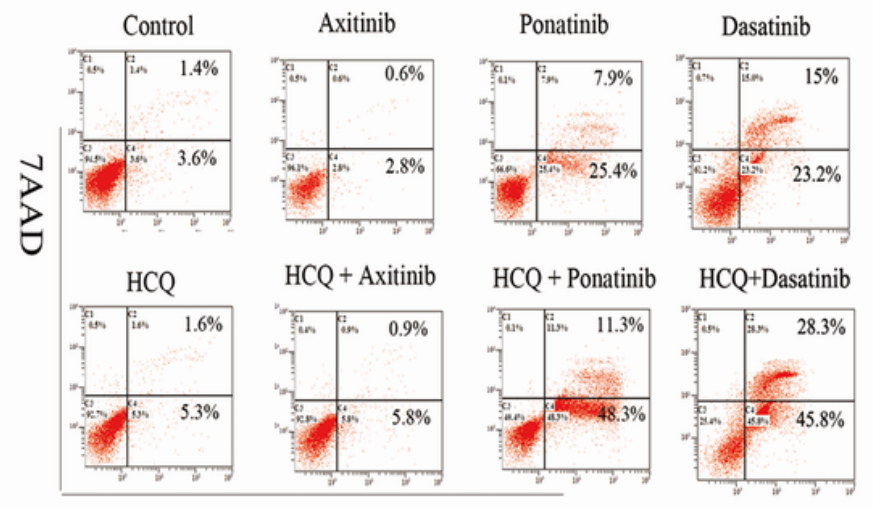

Annexin V -PE

d
32Dp210-T315I

$24 \mathrm{~h}$

$48 \mathrm{~h}$
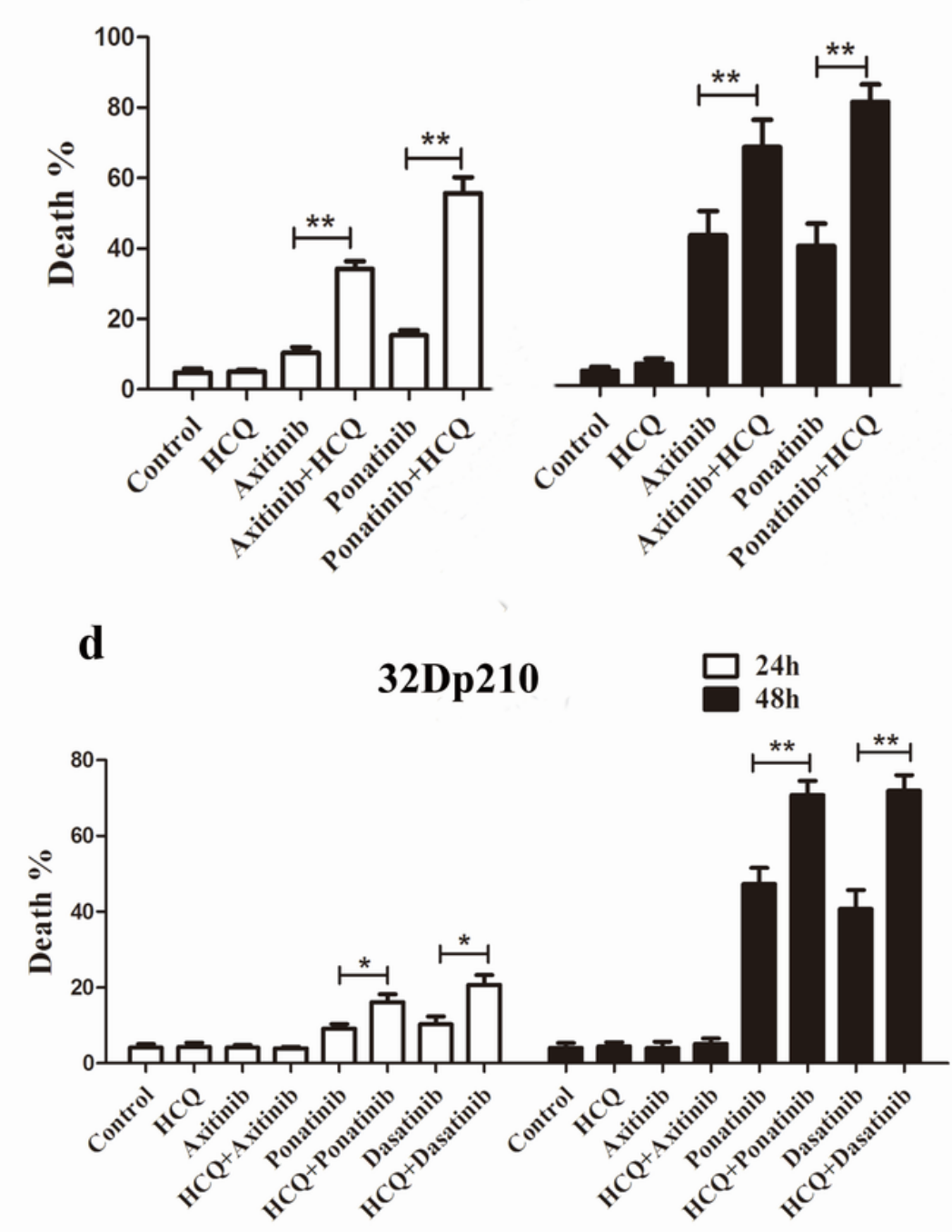

Figure 2

HCQ enhanced ponatinib- and axitinib-induced apoptosis in 32Dp210-T315I cells. a and b The apoptosis of 32Dp210-T315I cells after treated with ponatinib \pm HCQ and axitinib \pm HCQ. $c$ and $d$ The apoptosis of 32Dp210 cells after treated with ponatinib \pm HCQ axitinib \pm HCQ and dasatinib \pm HCQ 

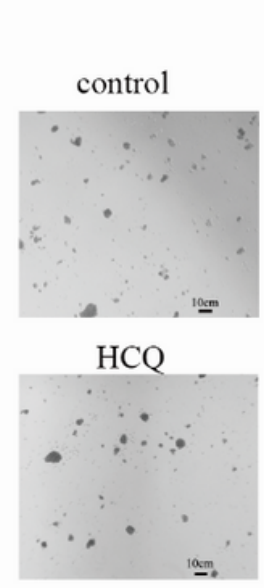

32Dp210-T315I

Axitinib

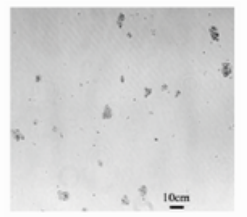

$\mathrm{HCQ}+$ Axitinib
Ponatinib

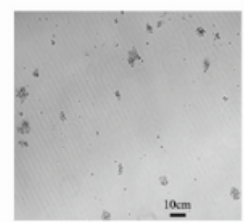

$\mathrm{HCQ}+$ Ponatinib

$\stackrel{10 \mathrm{~cm}}{-}$

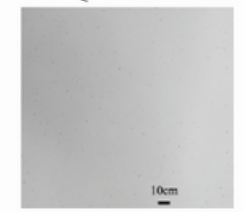

32Dp210-T315I

32Dp210

\section{Figure 3}

HCQ enhanced the inhibitory effect of ponatinib and axitinib on the clonality of 32Dp210-T315I cells. a The clonality of 32Dp210-T315I cells after treated with ponatinib \pm HCQ and axitinib \pm HCQ. b Statistical diagram of clone formation in 32D 210-T315I and 32D 210 cells treated with TKIs \pm HCQ.

a
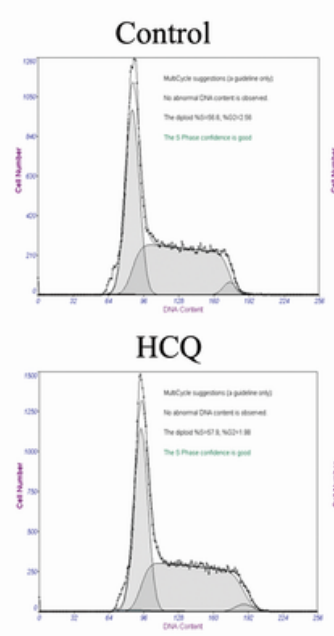

32Dp210-T315I

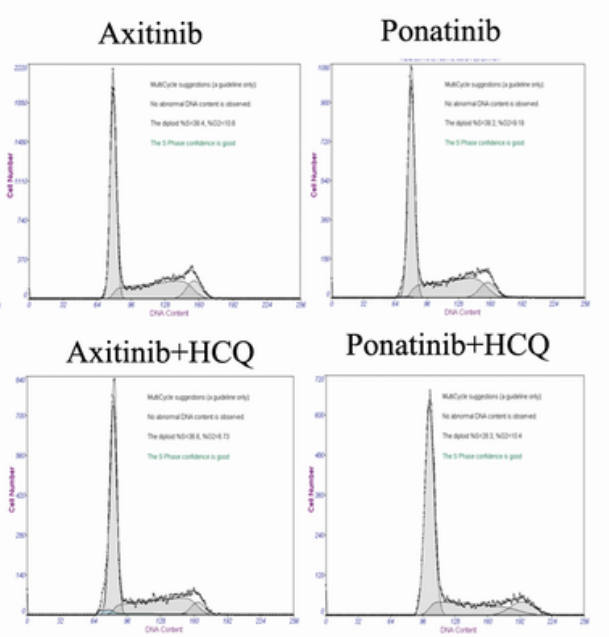

b

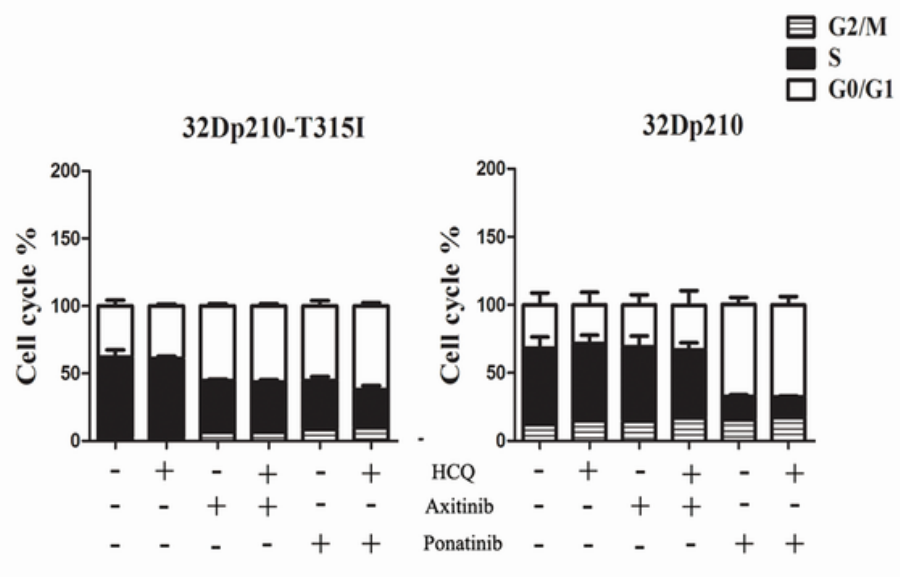

Figure 4

HCQ did not promote ponatinib- or axitinib-induced cell cycle arrest in 32Dp210-T315I cells. a The cell cycle of 32Dp210-T315I cells treated with ponatinib \pm HCQ and axitinib \pm HCQ. $b$ The statistical diagram of cell cycle in 32Dp210-T315I and 32Dp210 cells treated with ponatinib \pm HCQ and axitinib \pm HCQ . 


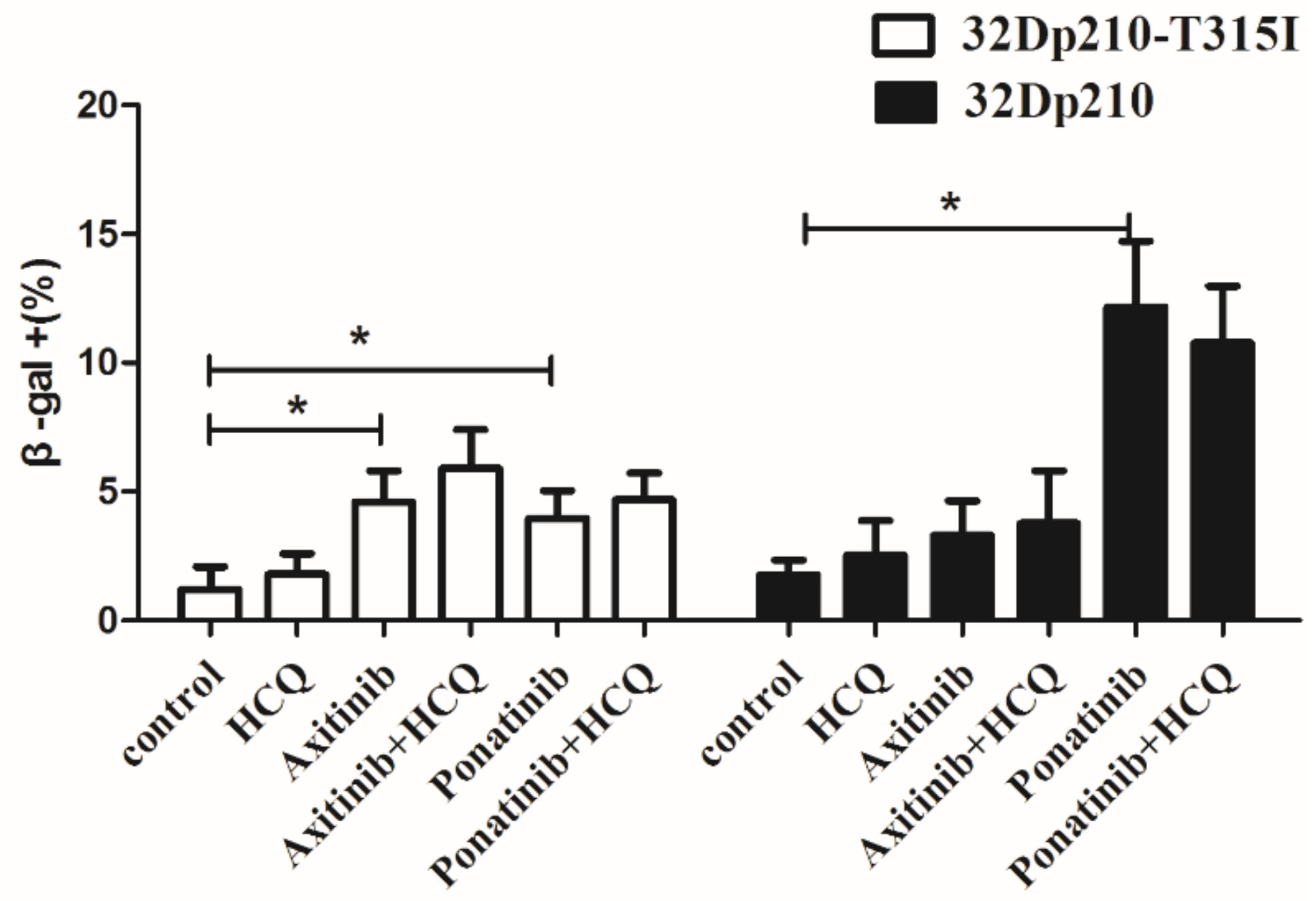

Figure 5

HCQ did not increase ponatinib- and axitinib-induced senescence in 32Dp210-T315I cells. 

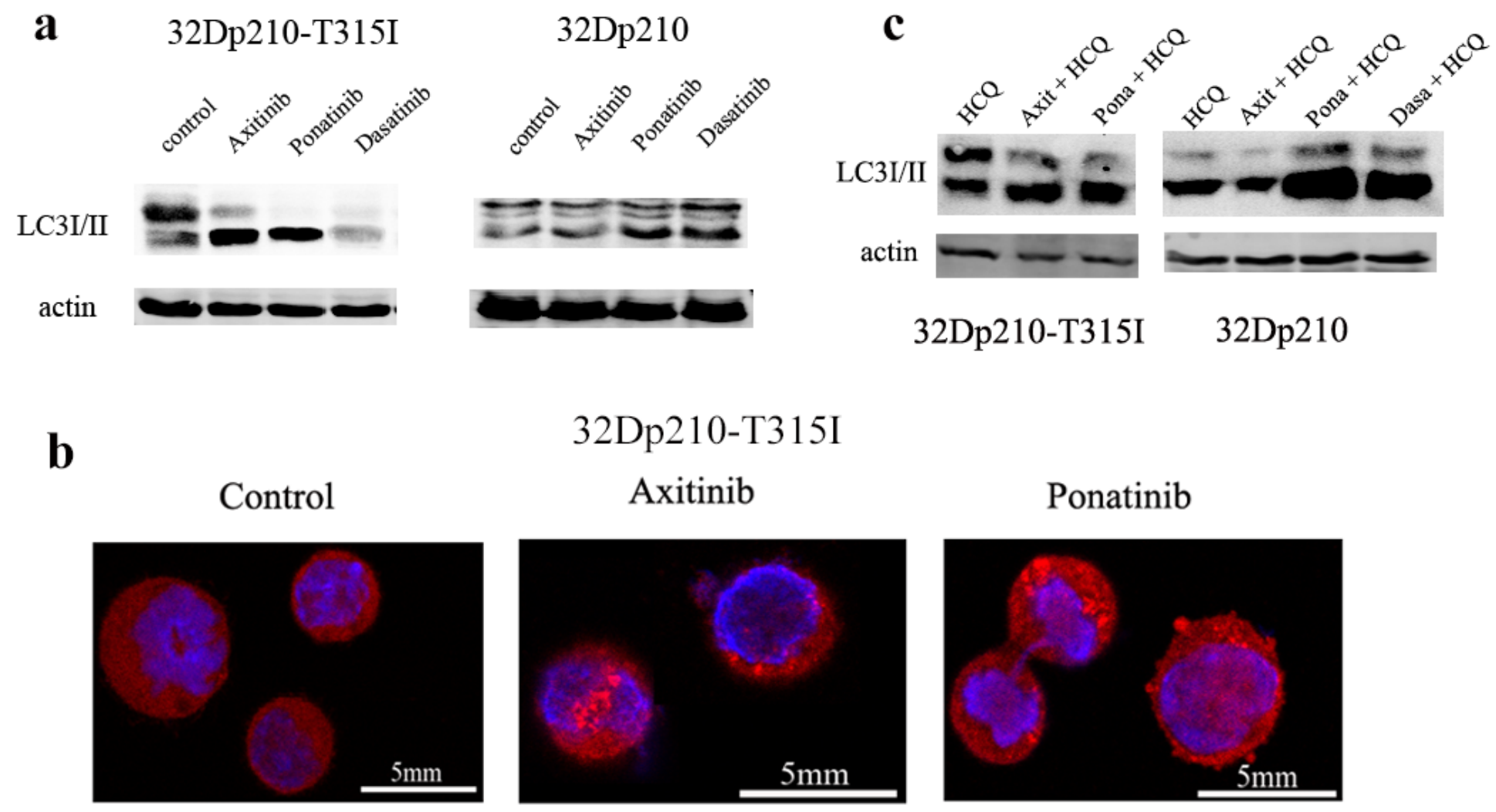

32Dp210-T315I

Axitinib

Ponatinib
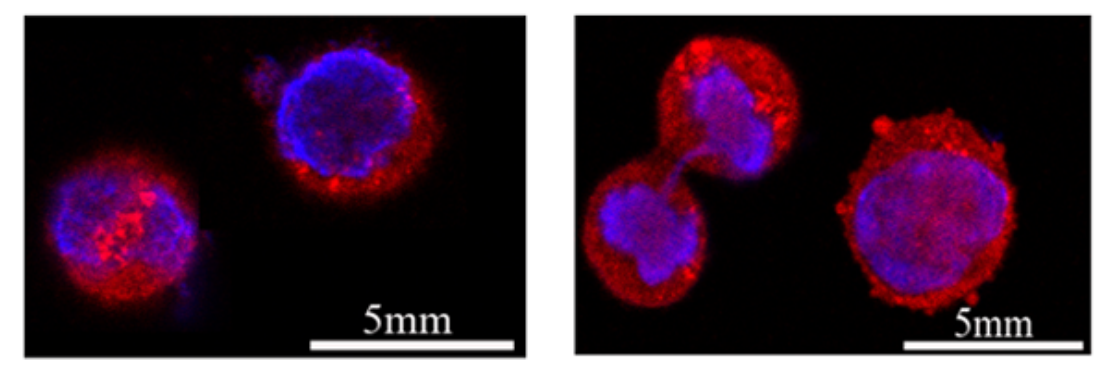

\section{Figure 6}

Ponatinib and axitinib induced autophagy in 32Dp210-T315I cells. a The expression of LC3I/II in 32Dp210-T315I cells (left) and 32Dp210 cells (right) in ponatinib axitinib dasatinib and control group. b Autophagosomes (the bright red point) in 32Dp210-T315I cells in ponatinib axitinib and control group. c After blocking autophagic flux with HCQ, the expression of LC3I/II in 32Dp210-T315I cells (left) and 32Dp210 cells (right) in ponatinib axitinib and control group.

\section{Dp210-T315I}
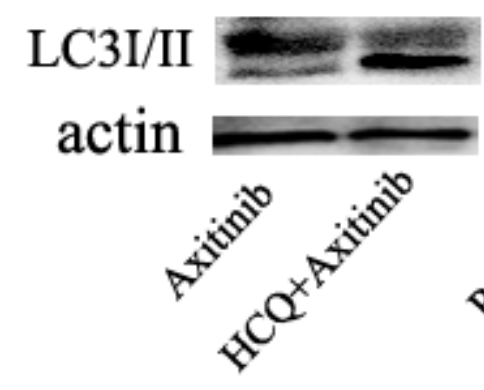
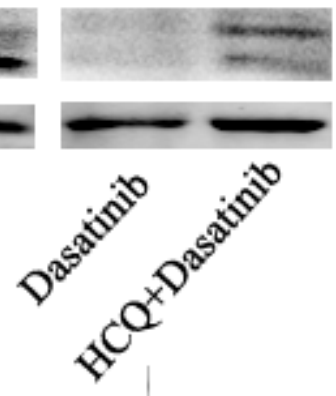

\section{Dp210}

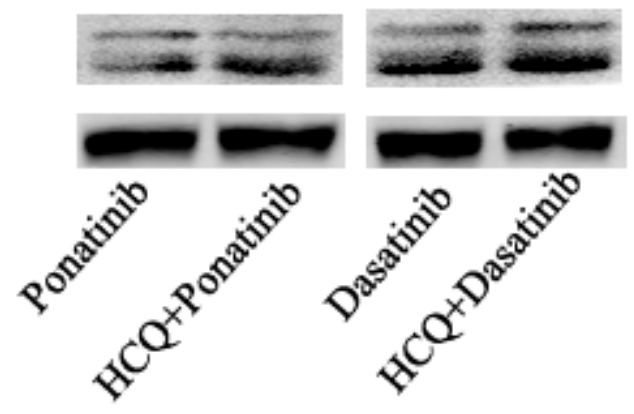

\section{Figure 7}

HCQ inhibited ponatinib- and axitinib-induced autophagy in 32Dp210-T315I cells. The expression of LC3I/II in 32Dp210-T315I and 32Dp210 cells after treated with ponatinib \pm HCQ axitinib \pm HCQ 
dasatinib $\pm \mathrm{HCQ}$.

a

\section{Dp210-T315I 32Dp210}

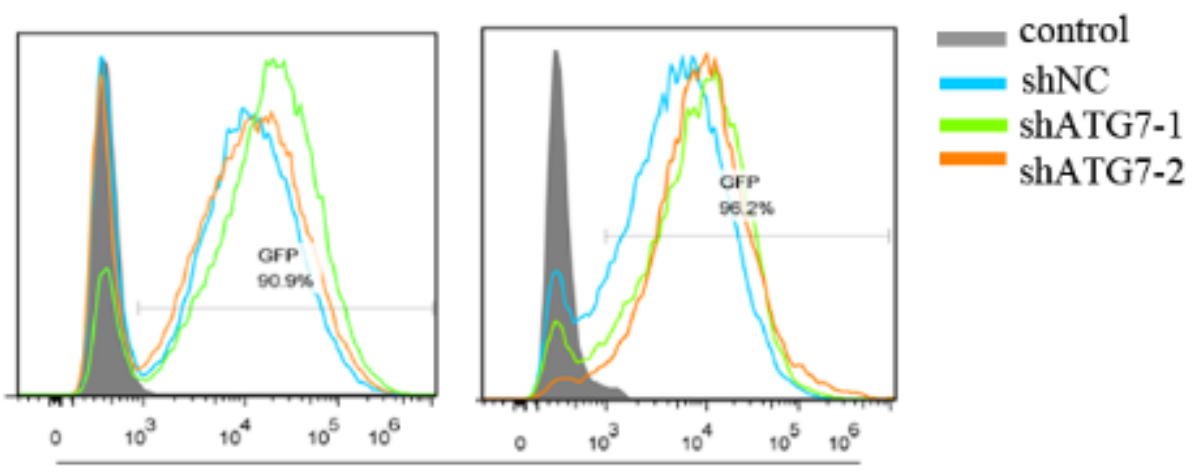

GFP

b

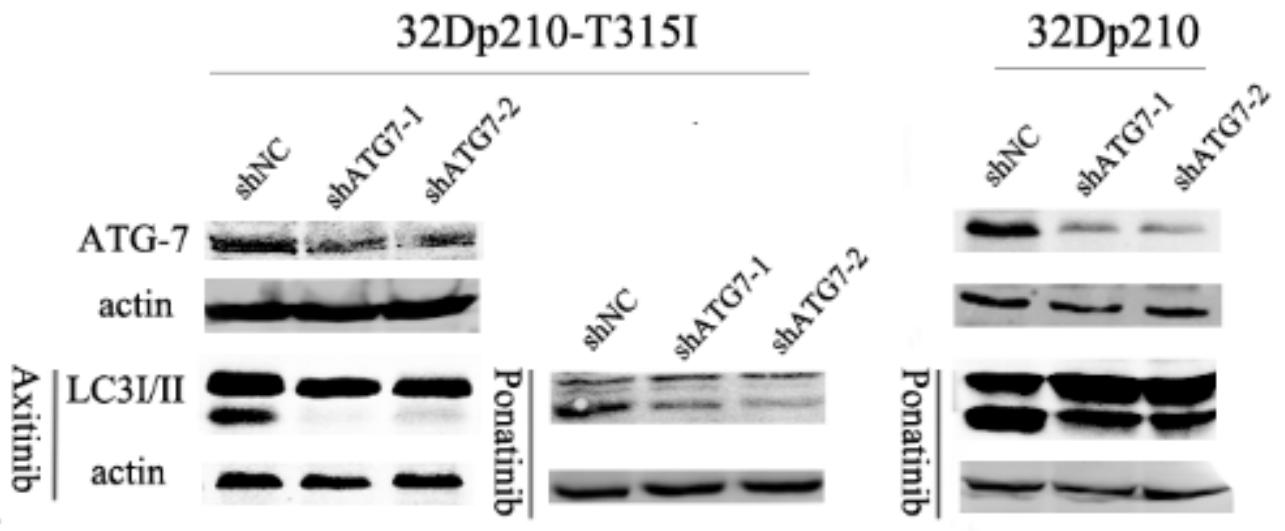

Figure 8

Knocking-down ATG7 inhibited ponatinib- and axitinib-induced autophagy in 32Dp210-T315I cells. a The proportion of GFP-positive cells detected by flow cytometry after lentiviral infection. b Compared to the negative control shRNA(shNC), shRNA-ATG7-1 and shRNA-ATG7-2 can effectively inhibit the expression of ATG7 protein in 32Dp210-T315I and 32Dp210 cells (upper), and inhibit autophagy induced by ponatinib and axitinib in 32Dp210-T315I and 32Dp210 cells (blow). 
32Dp210-T315I

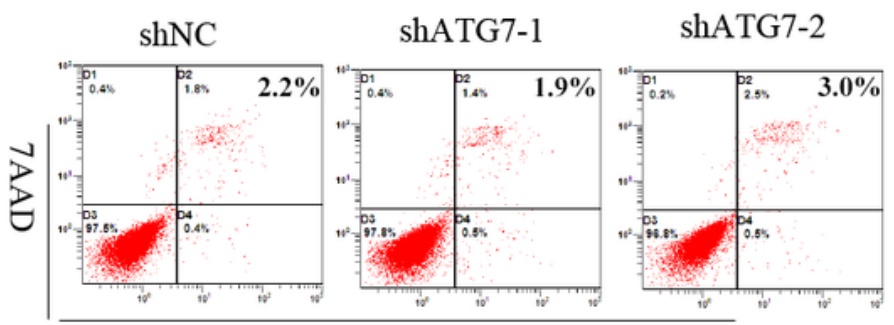

Annexin V

32Dp210

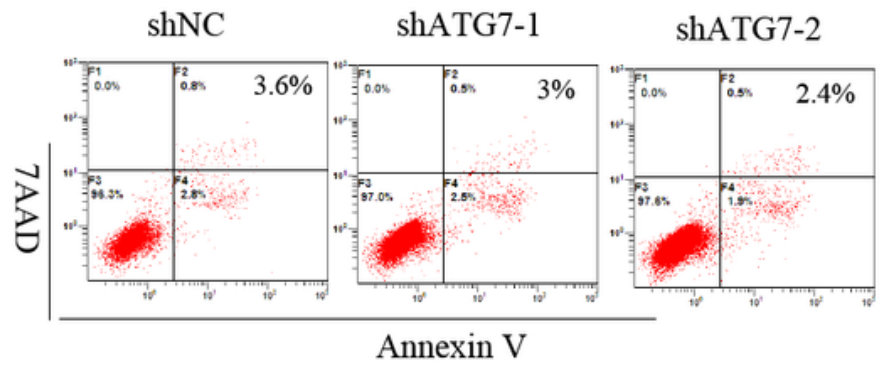

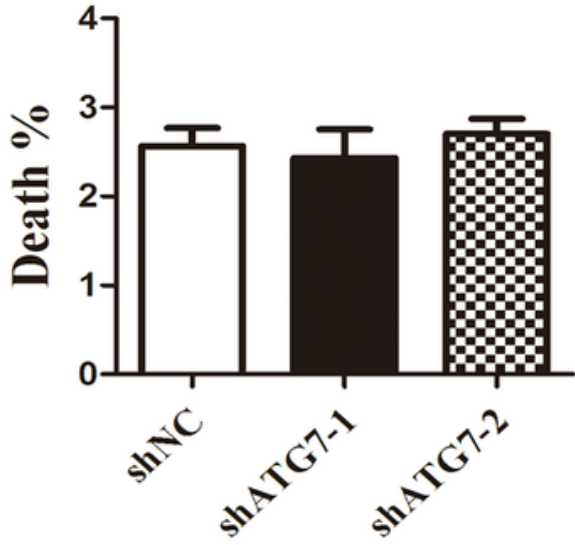

32Dp210

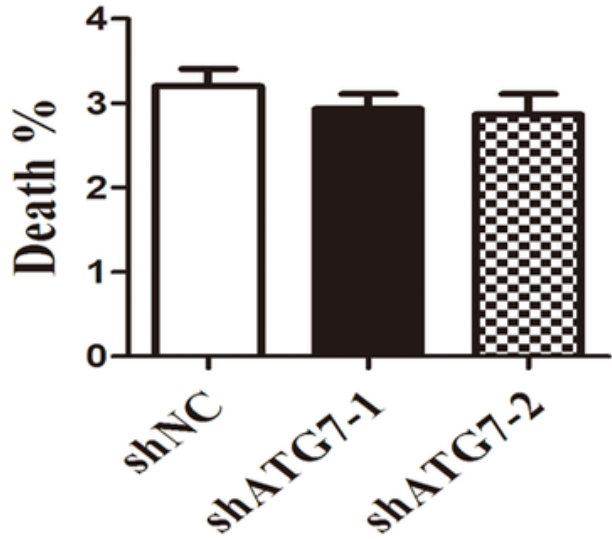

b

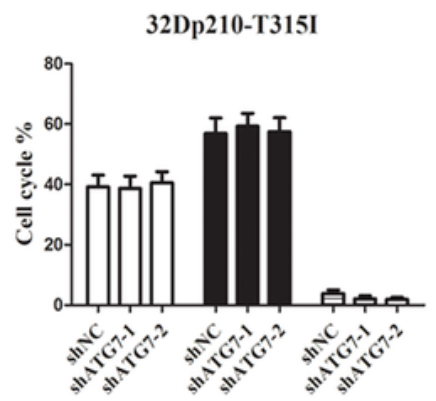

32Dp210-T315I

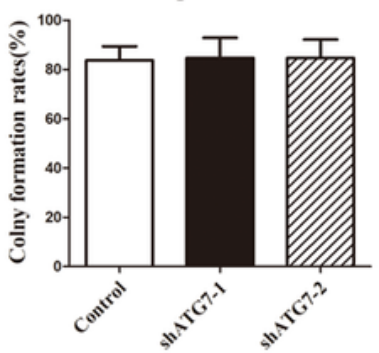

32Dp210

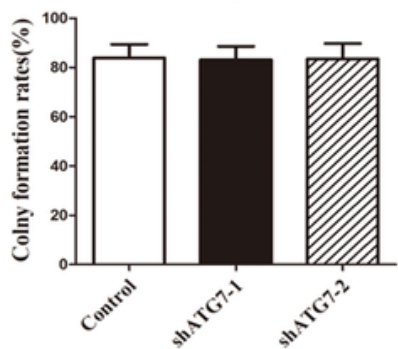

Figure 9

Knocking down ATG7 was nontoxic to 32Dp210-T315I and 32Dp210 cells. a Compared with controls, ATG-7 knockdown did not affect the cell apoptosis in 32Dp210-T315I and 32Dp210 cells. b The cell cycle distribution between ATG7-knockdown group and control group had no significant difference. c After in vitro culture for 7d, the colony formation rates in the control group and ATG7-knockdown group were similar. 

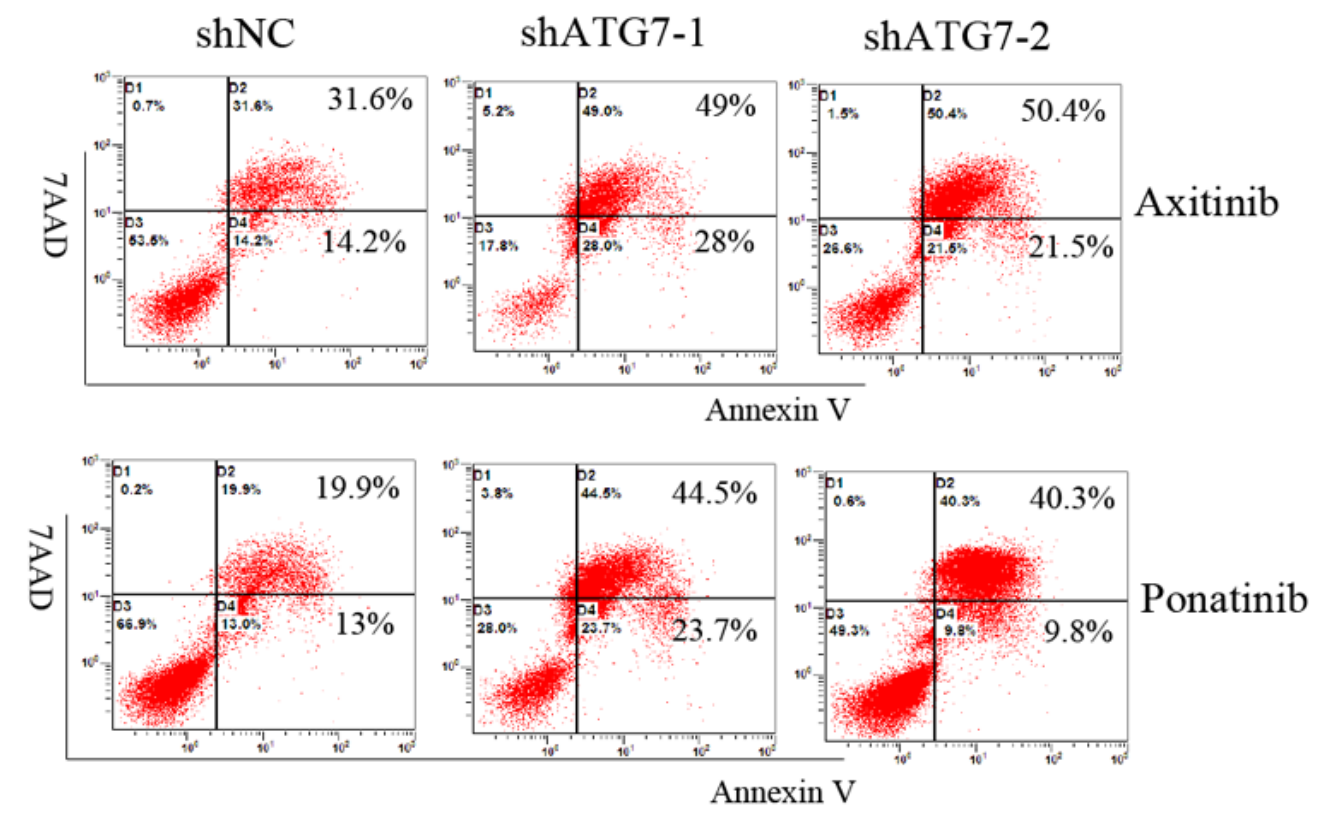

b
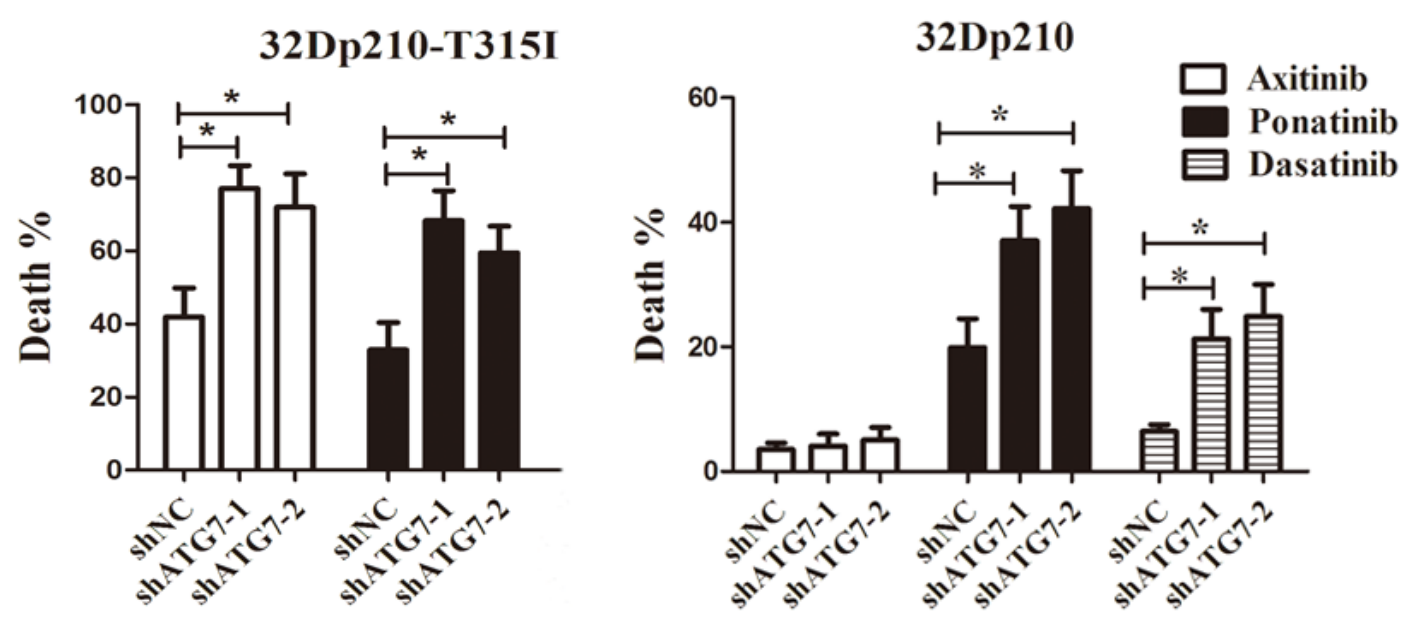

Figure 10

ATG7 knockdown enhanced ponatinib- and axitinib-induced apoptosis in 32Dp210-T315I cells. a Typical figure of cell apoptosis in ATG7-knockdown 32Dp210-T315I cells after treated with ponatinib and axitinib. b Compared to control cells, ATG7-knockdown 32Dp210-T315I cells were more sensitive to ponatinib and axitinib囚left \and ATG7-knockdown 32Dp210 cells were more sensitive to ponatinib and dasatinib(right). Data were presented as mean \pm SD $(* P<0.05)$. 
a

32Dp210-T315I

Axitinib
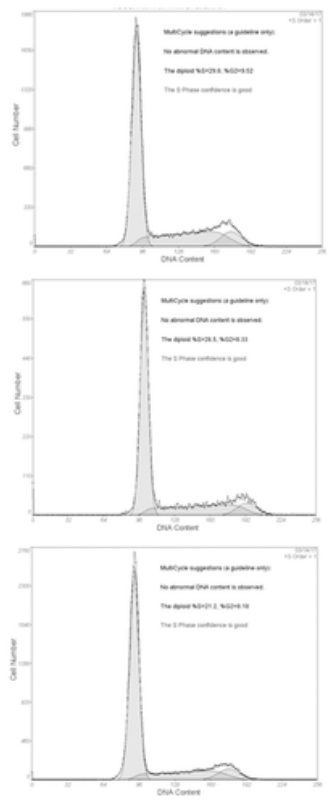

Ponatinib

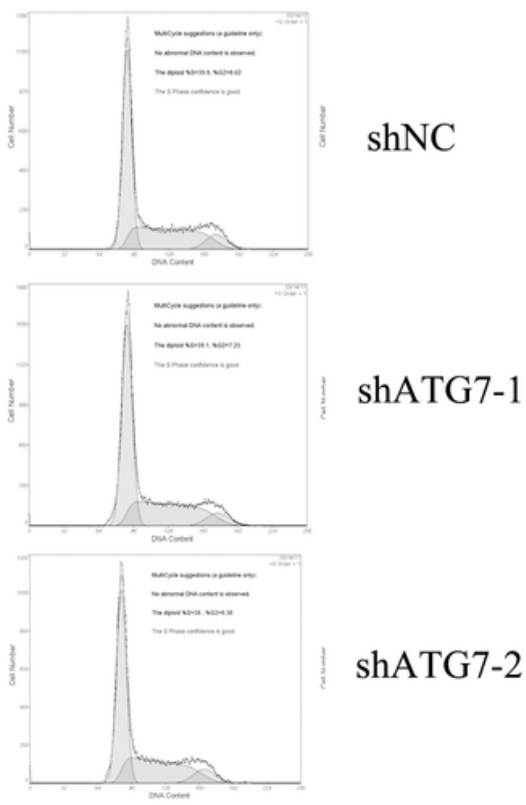

b

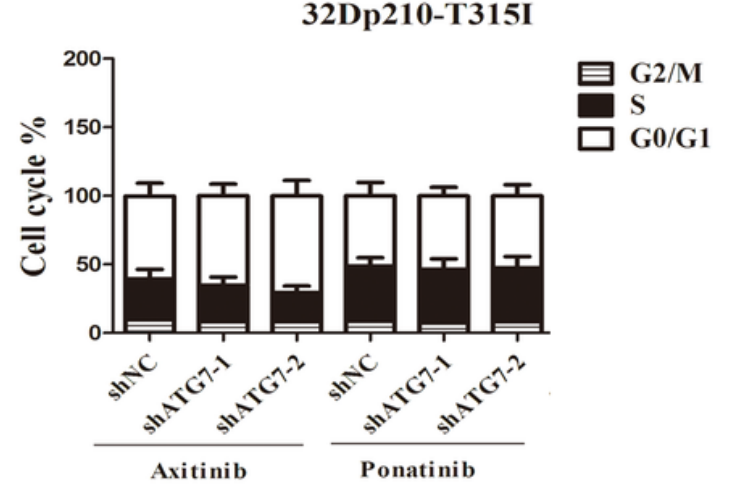

32Dp210

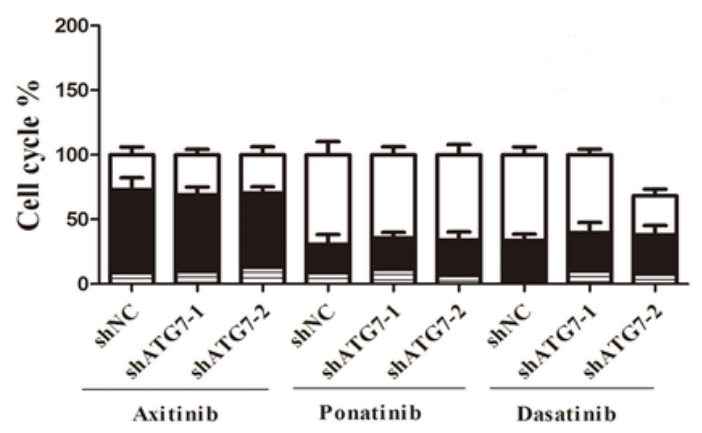

\section{Figure 11}

ATG7 knockdown did not influence the ponatinib- and axitinib-induced cell cycle arrest of 32Dp210-T315I cells. a Typical figure of cell cycle distribution in ATG7-knockdown 32Dp210-T315I cells after treated with ponatinib and axitinib. b After treated with ponatinib and axitinib , the cell cycle distributions have no statistical difference between control group and ATG7-knockdown 32Dp210-T315I (upper). Compared to the control group ATG7 knockdown did not affect the cell cycle distributions in 32Dp210 cells after treated with ponatinib axitinib and dasatinib(blow). 
a
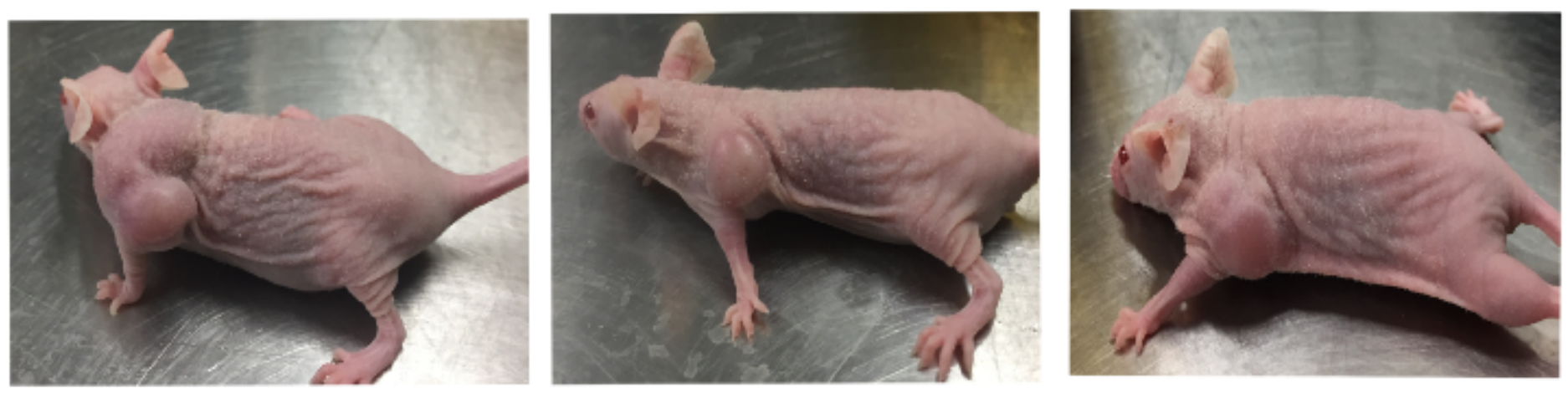

b

Tomour volum before treatment

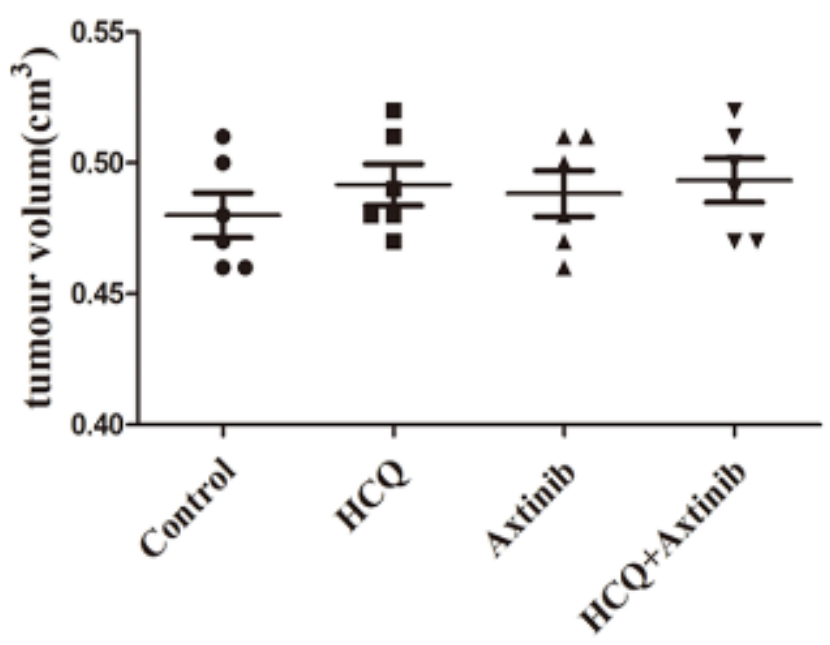

c

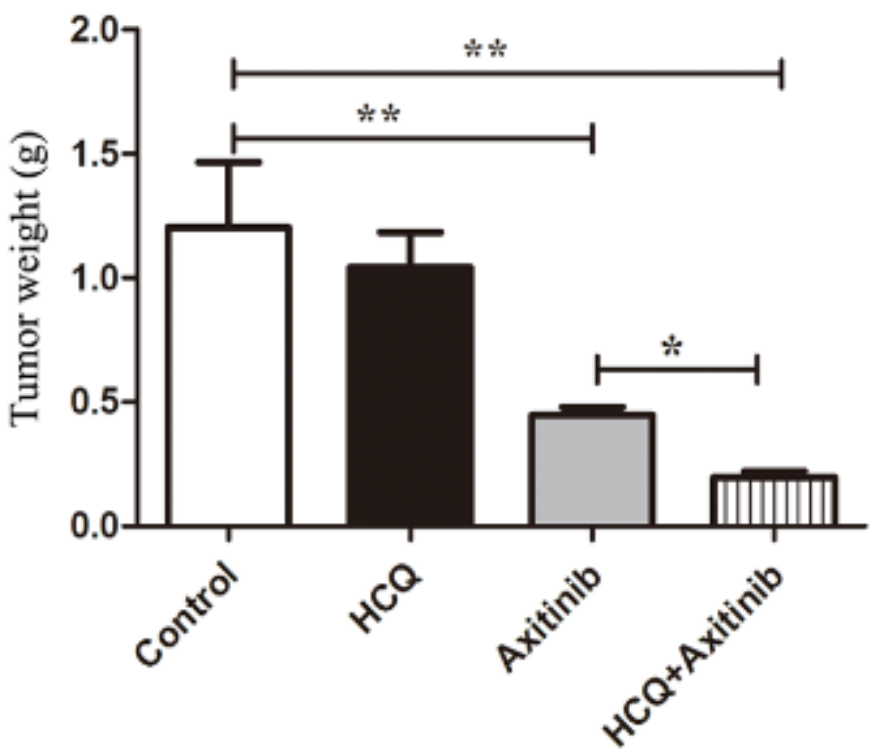

Figure 12

HCQ enhanced the killing effect of axitinib on 32Dp210-T315I cells in vivo. a The typical pictures of subcutaneous tumor in nude mice. $b$ The nude mice with tumor were divided into four groups and there were no statistical difference in the tumor volumes among groups before treatment. c After treating for ten days the tumor were weighted. The mean tumor weight in the HCQ+axitinib group was the lowest. 